\title{
El espejismo nacional-socialista. La relación entre dos catedráticos de Prehistoria, Oswald Menghin y Julio Martínez Santa-Olalla (1935-1952)
}

\author{
The National-Socialist Mirage. The relationship between two Professors of Prehistory, \\ Oswald Menghin and Julio Martínez Santa-Olalla (1935-1952)
}

\author{
Alfredo Mederos Martín (*)
}

\section{RESUMEN}

Oswald Menghin, Catedrático de Prehistoria del Hombre de la Universidad de Viena entre 1922-1945, fue partidario de la unidad de Austria con Alemania y simpatizante con ideas del NSDAP sobre la necesidad de evitar una mezcla racial entre arios y judíos. Durante su etapa como Catedrático-Residente en la Universidad de Fouad en El Cairo entre 1930-1933, por contacto con Hermann Junker, radicalizó sus puntos de vista y redactó su libro Espíritu y sangre. Principios básicos de raza, lengua, cultura y nación. Su etapa como Rector en el curso 1935-1936 le catapultó a la política como miembro del consejo directivo del partido fascista austriaco, Vaterländische Front, entre 1936-1937 y su posterior nombramiento como Ministro de Educación entre marzo y mayo de 1938, justo después de la invasión de Hitler de Austria. Siendo Ministro, solicitó su ingreso en el NSDAP, que no se aceptó hasta junio de 1940, por su pertenencia previa a organizaciones católicas secretas.

Menghin entró en contacto con Martínez Santa-Olalla, después de la celebración del Jubileo del Instituto de Morfología Cultural de Frankfurt en junio y julio de 1938. A raíz de una estancia de investigación de Almagro Basch en Alemania y Austria en enero y febrero de 1942, y la posterior visita a Barcelona de Menghin en junio de 1942, optó por distanciarse de Martínez Santa-Olalla, no visitando Madrid, cortando la relación epistolar e informando negativamente sobre él a las SS-Ahnenerbe.

Prisionero en dos campos de concentración norteamericanos entre mayo de 1945 y febrero de 1947, Menghin huyó a la Argentina en 1948, viajando poco después su mujer y su hija. En Argentina fue apoyado por José Imbelloni, director del Museo Etnográfico de la Universidad de Buenos Aires desde 1947, que lo contrató como investigador sin docencia. También recibió el apoyo de

*) Departamento de Prehistoria y Arqueología, Facultad de Filosofía y Letras, Universidad Autónoma de Madrid. Campus de Cantoblanco. 28049 Madrid, España.

Correo e.: alfredo.mederos@uam.es

Recibido 15-X-2012; aceptado 4-X-2013.
Martínez Santa-Olalla a través del Embajador de España, José María de Areilza, y del profesor de historia en la Universidad de Buenos Aires, Claudio Sánchez-Albornoz. Menghin no pudo impartir docencia hasta 1953 y solo consolidó su puesto una vez su proceso penal fue cancelado en diciembre de 1956, obteniendo en 1957 , con 69 años, el puesto de Profesor Interino de Prehistoria de la Universidad Nacional de La Plata y en 1958, la Cátedra de Prehistoria General y del Viejo Mundo en la Universidad de Buenos Aires, donde se jubiló en 1968, con 80 años.

\begin{abstract}
Oswald Menghin, Professor of Prehistoric Man at the University of Vienna from 1922-45, supported the unity of Austria with Germany, and a sympathizer about the NSDAP ideas on the need to avoid racial mixing between Aryans and Jews. During his time as Professor at the University of Fouad in Cairo from 1930-33 he came into contact with Hermann Junker. This radicalized Menghin's views and, as a result, he wrote his book, Spirit and Blood. The Basic Principles of Race, Language, Culture and Nation. His time as Rector of the University of Viena from 1936 to 1937 catapulted him into politics: he was a board member of the Austrian fascist party, Vaterländische Front from 1936 to 1937 and was appointed Minister of Education between March and May 1938, just after Hitler's invasion of Austria. As Minister, he applied for membership in the NSDAP, but because his prior membership in secret Catholic organizations, it was not accepted until June 1940.

Menghin was in contact with Martinez Santa-Olalla, after the celebration of the Jubilee of the Institute for Cultural Morphology at Frankfurt in June and July 1938. After Almagro Basch's research period in Germany and Austria in January and February 1942 and his own visit to Barcelona in June 1942, however, Menghin chose to distance from Martinez Santa-Olalla, not visiting Madrid, cutting the epistolary relationship and reporting negatively about him to the SS-Ahnenerbe.
\end{abstract}


After being imprisoned in two American concentration camps between May 1945 and February 1947, Menghin fled to Argentina in 1948, followed shortly afterwards by his wife and daughter. In Argentina Menghin was supported by Jose Imbelloni, director of the Ethnographic Museum at the University of Buenos Aires since 1947, who hired him as a researcher without teaching. He also received support from Martinez Santa-Olalla through the Spanish Ambassador, Jose Maria de Areilza, and from the Professor of History at the University of Buenos Aires, Claudio Sanchez-Albornoz. Menghin was not permitted to give lectures until 1953, and only consolidated his position when his criminal trial was cancelled in December 1956. In 1957 at the age of 69, he obtained the position of Acting Professor of Prehistory at the National University of La Plata. In 1958, Menghin was appointed Professor in General and Old World Prehistory at the University of Buenos Aires, where he retired in 1968, aged 80.

Palabras clave: Prehistoria; Historiografía; Política y Arqueología; Fascismo; Siglo XX; Nacional-Socialismo; Oswald Menghin; Martínez Santa-Olalla.

Key words: Prehistory; Historiography; Archaeology and Politics; Fascism; XXth century; National-Socialism; Oswald Menghin; Martinez Santa-Olalla.

\section{INTRODUCCIÓN}

Oswald Menghin, Catedrático de Prehistoria del Hombre de la Universidad de Viena entre 1922-1945, es uno de los principales prehistoriadores en Austria y Alemania en esas décadas. El análisis de su trayectoria pretende profundizar en los estudios previos de Urban (1996) o Kohl y Pérez Gollán (2002). Se aprovecha su relación con Julio Martínez Santa-Olalla, Catedrático interino de Historia Primitiva del Hombre en la Universidad de Madrid entre 1939-1954, para valorar la influencia de la ideología nacional-socialista en los 1930, cómo afectó a sus respectivas carreras universitarias y a su interrelación personal y científica.

\section{FORMACIÓN Y TRAYECTORIA ACADÉMICA DE O. MENGHIN}

Oswald Franz Ambrosius Menghin Terzer nació el 19 de abril de 1888 en Meran, Tirol austriaco, donde realizó sus estudios secundarios en el Gymnasium de Meran (Urban 1996: 4; Fontán 2005: 74 doc. 3). Comenzó en 1906 su carrera en la Universidad de Viena, con 18 años, donde ingresó también como miembro de la asociación estudiantil Katholische Österreichische Studentenverbindung (K.Ö.St.V.) Rudolfina Wien, integrante desde 1906 de la asociación católica, Cartellverband der katholischen deutschen Studentenverbindungen (Cartel de asociaciones católicas alemanas de estudiantes) (Geehr 1986: 16). Junto a su padre, Alois Menghin, director de escuela y aficionado a la arqueología, hizo sus primeras excavaciones entre 1911-1916(Menghin 1956) en el poblado fortificado de las Edades del Bronce y del Hierro de Ganglegg, en el Sur del Tirol, cuyo estudio acabó publicando. Alois admiraba al poeta Richard Kralik von Meyrswalden, defensor de una cultura alemana pura y de la recuperación del Sacro Imperio Romano Germánico. En 1901, regaló a su hijo con 13 años un libro de Kralik, indicándole que, cuando lo comprendiese, habría madurado (Geehr 1986: 13-14, 2003: 136). No debe olvidarse en la personalidad de Menghin que también fue poeta y novelista.

En 1910, a los 22 años, se doctoró con el trabajo Beiträge zur ältesten Siedelungs- und Agrargeschichte Deutschtirols (Contribución a la Historia Antigua del poblamiento agrario del Tirol alemán). Realizó el examen de Estado en 1911. Su habilitación con Urgeschichte des Menschen (Prehistoria del Hombre), en 1913, le permitió acceder, en 1918, al puesto de Privatdozent o Profesor Extraordinario de Arqueología Prehistórica (Narr 1974: 1; Fontán 2005: 74, doc. 3). Ocupó la plaza de Moriz Hoernes que detentó la cátedra desde 1911 hasta su muerte el 10 de julio de 1917. Sirvió en el frente durante la Primera Guerra Mundial (Fontán 2005: 74, doc. 3). Desde 1911 hasta su nombramiento como Privatdozent en 1918 sus principales ingresos económicos fueron como funcionario en el Archivo Regional de Baja Austria (Urban 1996: 4; Fontán 2005: 83, doc. 8).

Hoernes tardó 12 años en llegar a la cátedra, pero Menghin solo 5. En 1921 fue propuesto como catedrático de Prehistoria en la Universidad Alemana de Praga (Pittioni 1974: 2) y en 1922, con 34 años, nombrado catedrático u ordentlicher Professor de Urgeschichte des Menschen en la Universidad de Viena. Este cargo supuso también su nombramiento como director del Urgeschichtlichen Institut de dicha Universidad hasta 1930 (Fig. 1). 


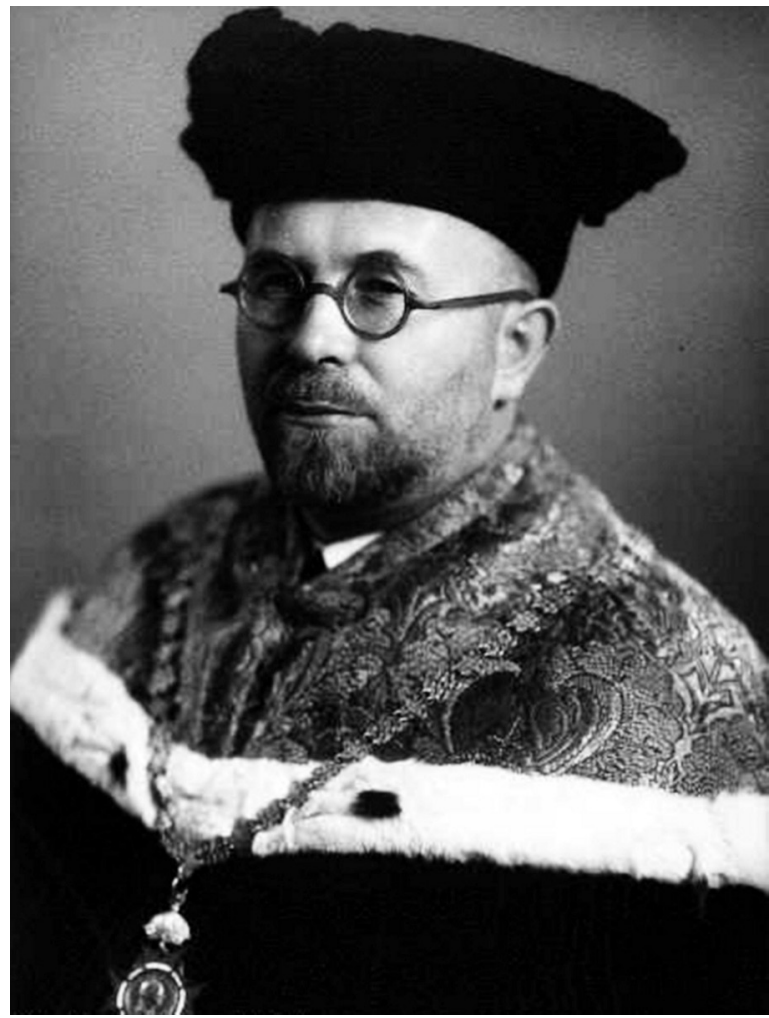

Fig. 1. Oswald Menghin, Rector de la Universidad de Viena, curso 1935-1936 (Universität Wien).

Desde que fue nombrado Profesor Extraordinario en Arqueología Prehistórica en 1918 mostró su orientación política, partidaria de la unión con Alemania. Ello le llevó a integrarse en 1919 en la Deutschen Gemeinschaft (Comunidad Alemana), sociedad "antimasónica y antisemita" según el Nationalsozialistische Deutsche Arbeiterparte (NSDAP Partido Nacional-Socialista Alemán de los Trabajadores) (Rosar 1971; Geehr 1986: 17, 2003: 138; Urban 1996: 11, doc. 2), donde permaneció hasta 1926. Allí conoció a Arthur SeyssInquart, futuro Canciller. Retomaron los contactos en el verano de 1932 (Urban 1996: 21, n. 68), año en que empezó a colaborar con el movimiento estudiantil nazi durantes los conflictos universitarios, según indicó en su solicitud de afiliación al NSDAP (Urban 1996: 11, doc. 1).

En 1923, al año de ser catedrático, pronunció su primera conferencia sobre "La cuestión judía" en la delegación local del XVIII distrito vienés de Währing del NSDAP, según señalaba en su solicitud de afiliación al mismo en 1938 (Urban 1996: 11, doc. 1). Menghin residía en este distrito, en la calle Eckpergasse 14.
En el curso 1928-1929 fue nombrado Decano de la Facultad de Filosofía de la Universidad de Viena hasta trasladarse como Catedrático-Residente, durante los tres semestres de invierno entre 1930 y 1933, a la Universidad de Fouad, en El Cairo (Pittioni 1974: 3; Trebsche 2005: 182), mientras excavaba en Merimde-Beni Salâme y Maadi. Trabajando con Hermann Junker (Fig. 2) inició su vinculación con Egipto. Junker, nacido en Bendorf am Rheim (Renania-Palatinado, Alemania), doctorado en 1903 en la Universidad de Berlín y habilitado en 1907 en la Universidad de Viena, accedió a la Cátedra de Egiptología de dicha universidad en 1912. En 1929 fue nombrado simultáneamente Director del Instituto Arqueológico Alemán en El Cairo y Profesor de Egiptología en la Universidad de Fouad. Afiliado al NSDAP, continuó impartiendo docencia como Profesor Honorario en la Universidad de Viena. Entre 1928 y 1939, Junker dirigió 7 campañas de excavación en Merimde-Beni Salâme (Junker 1932, 1933, 1934, 1940). Menghin (1942a: 28) participó en 4 de ellas y completó esta investigación en Maadi, actual Uadi el-Tih, hoy en la periferia de El Cairo, junto a Mustapha Amer, Profesor de la Universidad de El Cairo. Allí excavaron durante 6 campañas entre 1930-1939. Menghin participó en las dos primeras: 1930-1931 y 1932 (Menghin y Amer 1932, 1936). En 1931 fue nombrado jefe de la Sección de Prehistoria del Naturhistorischen Museum de Viena, cargo que detentó hasta 1935, cuando accedió al rectorado.

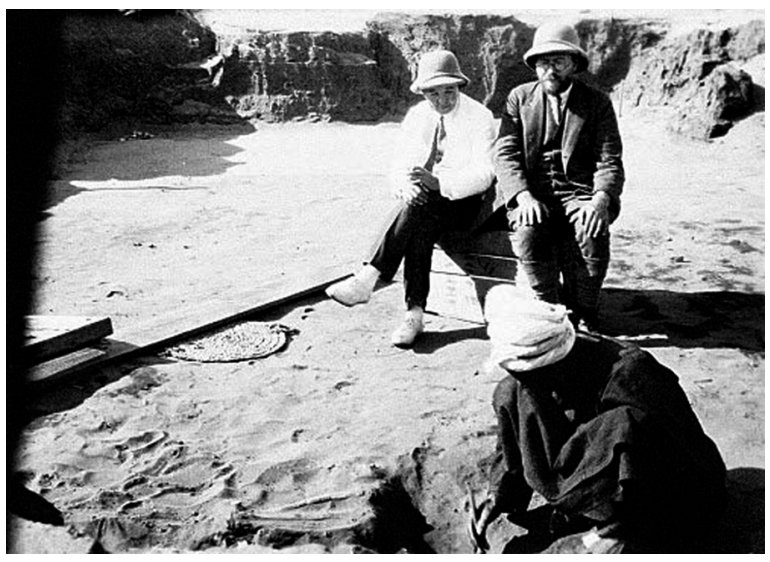

Fig. 2. Hermann Junker, Director del Instituto Arqueológico Alemán de El Cairo y codirector con Menghin de las excavaciones de Merimde-Beni Salâme entre 1930-33 (Örsterreichische Akademie der Wissenschaften-ÖAW). 
También en 1931 publicó su trabajo científico más relevante, Weltgeschichte der Steinzeit (Historia Universal de la Edad de la Piedra), que abarcaba la Prehistoria mundial desde el Paleolítico hasta el Calcolítico. Dividía el primero en Protolítico (Paleolítico Inferior y Medio) y Miolítico (Paleolítico Superior), identificando en ambas fases tres grandes círculos culturales: las culturas de las hojas, de las hachas y del hueso. Además, dividía el Neolítico en Protoneolítico, o etapa de la domesticación y el Mixoneolítico (Neolítico Medio-Calcolítico), a su vez, con tres grandes círculos culturales: el de las culturas de las estepas o pastores guerreros, heredera del círculo del hueso; el de las culturas rurales, herederas del círculo de las hachas en la que incluía yacimientos como Beni-Salâme, Almizaraque, Los Millares o el megalitismo europeo; y el de la cultura urbana, heredera de la cultura de las hojas, presente en Susa, Ur, Troya, Cíclades o el Imperio Antiguo egipcio.

En 1933, antes de abandonar El Cairo, con 45 años, pronunció otra conferencia sobre 'La cuestión judía' en la delegación local del NSDAP, recogida en la solicitud de afiliación ya citada (Urban 1996: 11, doc. 1). En esta etapa en El Cairo parece experimentar una clara radicalización en sus planteamientos, que plasmó a inicios de 1934 en su libro "Espíritu y sangre. Principios básicos de raza, lengua, cultura y nación" (Menghin 1934a). Entre los 10 ensayos recogidos, destacan el noveno, Über Volkstum (Sobre la nacionalidad) $\mathrm{y}$, en particular, el décimo, Die wissenschaftlichen Grundlagen der Judenfrage (Los fundamentos científicos de la cuestión judía).

La influencia de Junker se explica bien a partir de una carta, actualmente en el archivo del Oriental Institute de la Universidad de Chicago, enviada por Georg Steindorff a John Albert Wilson en junio de 1945. El primero, Catedrático de Egiptología de la Universidad de Leipzig hasta 1934 y exiliado a Estados Unidos desde marzo de 1939 por la persecución a los judíos, escribe al segundo, Catedrático de Egiptología de la Universidad de Chicago que: Junker "usó su puesto y el Instituto estatal para promover la propaganda nazi. El Instituto estuvo siempre disponible para reuniones de los nazis, y la casa de Junker estuvo siempre abierta para invitados nazis, principalmente austriacos" (Oriental Institute Research Archive, Chicago).

\section{O. MENGHIN Y 'EL PROBLEMA JUDÍO'}

En las conferencias que impartió en 1923 y 1933, Menghin defendió la necesidad de resolver el problema de los judíos (Urban 1996: 5-8; Fontán 2005: 28-35), "Cuanto más claramente conozcamos las condiciones bajo las cuales ha surgido el problema judío, tanto más sencillamente arribaremos a una decisión vinculante para todos, de cómo tratarlo para poder superar sus efectos perniciosos" (Menghin 1934a: 148). También como católico nacional-socialista, consideraba que "Desde el punto de vista de la religión cristiana, el destino del judaísmo en la dispersión es el cumplimiento de un castigo divino ante cuya tragedia el creyente se inclina con veneración" (Menghin 1934a: 148). Además defendía la primacía de su raza: "Nadie que no esté dispuesto a reconocer la superioridad de la raza blanca sobre todas las demás, tal como sucede en la actualidad, puede discutir con fundamento" (Menghin 1934a: 150). En ella, los germanos tenían una posición preeminente. El "sueco (...) se podría hacer alemán si quisiera, nadie le pondría obstáculos (...) lo racial y cultural del sueco nos es tan cercano que él siempre podrá hallarse en el pueblo alemán (...) a los franceses y españoles se los miraría con mucho más escepticismo (...) Un árabe no sería reconocido como alemán, pero sus hijos y nietos de madres alemanas tendrían posibilidades de ser tomados por alemanes, aún cuando no como alemanes completos (...) Los negros y descendientes de negros podrán ser tomados siempre por cuerpos extraños, aún cuando adopten el idioma y la cultura alemanes" (Menghin 1934a: 167168).

El "campesinado germánico fue un campesinado guerrero. Por lo tanto, la contraposición espiritual entre judaísmo y alemanes es particularmente grande, mucho mayor que entre los judíos y las naciones del sur y oeste de Europa, entre las cuales la cultura urbana y enferma es más antigua y por lo tanto el ser judío llama menos la atención" (Menghin 1934a: 171). Entre "los judíos como mezcla específica de razas (...) la proporción de sangre de las razas del sur europeo tiene un rol preponderante y por el contrario, entre ellos solo se encuentran muy pocos elementos de razas boreales (...) los judíos también han incorporado elementos negroides $\mathrm{y}$ otros muy primitivos en medida no despreciable, 
un hecho que muchas veces se pasa por alto en silencio, pero que no obstante es innegable. Además, el judaísmo del este ha sufrido una influencia mogoloide difícil de estimar" (Menghin 1934a: 150). Por ello, "El hecho de que los judíos son racial y culturalmente algo distinto que las diferentes naciones de Europa es seguro, y del mismo modo lo es que se los percibe como tanto más extraños, cuanto más se va al norte de nuestro continente. A esto se suma el hecho de su cantidad no despreciable" (Menghin 1934a: 169). Como resultado, "Las tensiones entre los judíos y las naciones europeas aumentan cuanto más se va al norte" (Menghin 1934a: 149).

Partidario de la higiene racial, desde su punto de vista, "una nación será tanto más equilibrada y fuerte, cuanto más hayan progresado en ella los procesos de formación racial y viceversa" (Menghin 1934a: 135). Por tanto planteaba "¿Existe un derecho para impedir al judaísmo el ingreso en la comunidad alemana? (...) Cada pueblo tiene no solo el derecho sino también la obligación moral de defender a su nación. La admisión del judaísmo en la nación alemana (...) significaría exponer a la nación alemana al peligro de modificar su idiosincrasia" (Menghin 1934a: 140). Por ello, "sin lugar a dudas, la incorporación del judaísmo a lo alemán (...) tendría por consecuencia el peligro de una modificación del carácter de la nación alemana, un peligro tanto más acuciante, cuanto la peculiar estructura social del judaísmo no permitiría una mezcla homogénea, sino solamente un entrecruzamiento en el estrato superior de lo alemán” (Menghin 1934a: 170-171). Desde esta perspectiva, consideraba "confirmado que cruces entre razas muy distantes desencadenan tensiones peligrosas tanto entre individuos aislados como en la masa, que se deben definir como indeseables" (Menghin 1934a: 141). Por lo tanto, "Si a cada nación le corresponde una mezcla racial específica y esta mezcla determina al menos en parte el alma de la nación, entonces esta nación sin lugar a dudas tiene derecho a tomar las medidas para conservar los fundamentos de sus particularidades" (Menghin 1934a: 142). Esgrimía la audacia de sus planteamientos en una carta de 6 de mayo de 1941, en plenas victorias militares del Tercer Reich: "solo quiero destacar que mi libro Geist und Blut fue escrito en una época [1934] en que una publicación de estas características requería más coraje que hoy" (Fontán 2005: 80, doc. 6).

\subsection{O. Menghin, Rector de la Universidad de Viena en el curso 1935-1936}

Menghin, con su experiencia previa como Decano, fue elegido Rector de la Universidad de Viena durante el curso 1935-1936, sustituyendo al Catedrático en Derecho Internacional, Alexander Hold-Ferneck (curso 1934-1935). Este puesto facilitó su elección en 1936 como académico de número de la Österreichische Akademie der Wissenschaften (Academia Austriaca de Ciencias). En 1937 la Universidad de Göttingen le nombró Doctor Honoris Causa.

Según su solicitud de afiliación al NSDAP, durante el desempeño de su puesto de Rector, apoyó a estudiantes nazis sancionados (Urban 1996: 11, doc. 1) y un informe del NSDAP de octubre de 1941 indica que "era tratado de 'nazi' en la universidad” (Fontán 2005: 82, doc. 7).

Inmediatamente finalizado su cargo como Rector, empezó a vincularse a la política al ser elegido, el 11 de julio de 1936, como representante de la 'oposición nacional' en el consejo directivo del Vaterländische Front (Urban 1996: 12, doc. 3), partido fascista austriaco fundado el 20 de mayo de 1933 por el canciller Engelbert Dollfuss, que disolvió el parlamento el 4 de marzo de 1933 e inició una Dictadura. En el mismo consejo del Frente Patriótico entró Arthur Seyss-Inquart, junto al que permaneció Menghin hasta julio de 1937. Al dejarlo, Menghin se incorporó al Siebenerausschuss, Comité de los Siete de la Universidad de Viena, autorizado por el Canciller austriaco, Kurt von Schuschnigg (Urban 1996: 12, doc. 5), Ministro de Educación con Dollfuss hasta su asesinato en 1934, cuando lo sustituyó. En dicho Comité participaban miembros importantes del NSDAP, como Josef Leopold, nombrado jefe del partido en Austria en noviembre de 1936 por Hitler y Leo Tavs, segundo jefe del partido, para promover la cooperación entre el Vaterländische Front y el NSDAP. Además planificaron un nuevo golpe de estado, el denominado "plan Tavs", abortado por la policía en enero de 1938 (Whiteside 1965: 355, 357). 


\subsection{O. Menghin, Ministro de Educación (marzo-mayo 1938) y el inicio de la depuración de los judíos en la universidad austriaca}

El 12 de febrero de 1938 Hitler dio un ultimátum al Canciller Federal austriaco, Kurt Schuschnigg, perteneciente al ala derecha del Partido Social Cristiano, para integrar miembros del partido nazi en el gobierno. El 14 de febrero Arthur Seyss-Inquart, presidente de Liga austro-alemana, entró como Ministro de Interior y Seguridad, al ser el máximo representante de la 'oposición nacional' en la que se incluía Menghin. Ello implicó la excarcelación de muchos militantes del NSDAP, culpables de disturbios y atentados. A las 10 de la noche del 11 de marzo, Hitler ordenó la invasión de Austria. En la madrugada del 12 de marzo de 1938, Arthur Seyss-Inquart, nombrado Canciller, anunció su gobierno con Oswald Menghin como Ministro de Educación, cargo en el cual permaneció hasta el 31 de mayo o inicios de junio. Ni él, ni los ministros Neumayer y Wolf pertenecían aún al NSDAP. El 10 de abril, este nuevo gobierno excluía a los judíos del referéndum convocado para ratificar el paso de Austria a provincia del Imperio Alemán.

Dos meses antes del nombramiento de Menghin como Ministro, en un informe del NSDAP vienés de 7 de enero de 1938, se indicaba que "ha actuado con espíritu nacional, se recomienda un posible nombramiento" (Fontán 2005: 70, doc. 2). Ello sugiere que ya se barajaba su nombre para el ejecutivo nacional-socialista por el cual presionaba Hitler.

Arthur Seyss-Inquart, en su telegrama a Hitler de 12 de marzo, justificó la entrada de tropas alemanas y la unificación o Anschluss. El día 13 ingresó en el Partido Nacional-Socialista como SS-Gruppenführer (General de División). Ese mismo día Hitler atravesó la frontera entrando en su pueblo natal Braunau am Inn. El 15 dio un discurso aclamado por 250.000 personas en la Heldenplatz (Plaza de los Héroes): “Como Führer y canciller de la nación alemana y del Reich [Imperio], declaro ahora ante la historia la incorporación de mi tierra natal al Reich alemán" (Rosar 1971) (Fig. 3).

Menghin, para obviar que firmó la convocatoria del referéndum del 10 de abril, indicó: "no asistí a la reunión de gabinete del 13/3/1938, durante la que se resolvió la Ley de Anexión. En

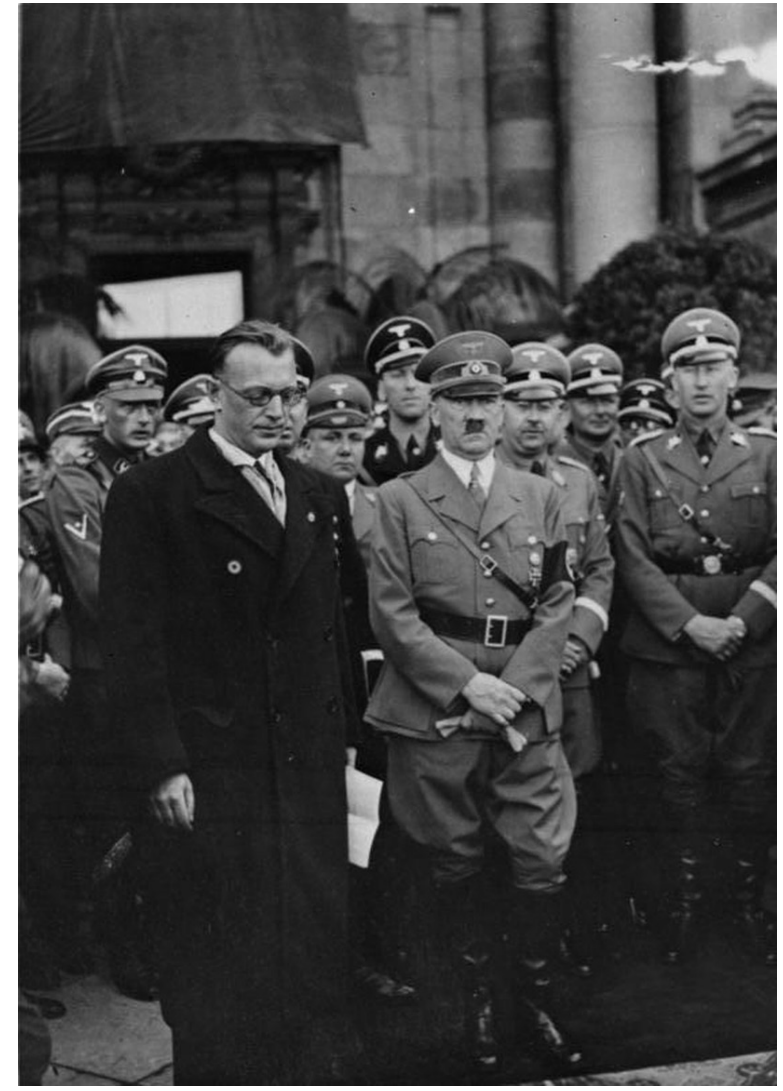

Fig. 3. Arthur Seyss-Inquart, Canciller de Austria desde el 12 de marzo de 1938, Adolf Hitler, Heinrich Himmler y Reinhard Heydrich, cuatro días después del Auschluss o unificación (Wien, 16-3-1938, Bundesarchiv, Bild 1195243, Koblenz).

ese momento me encontraba con el presidente federal, Wilhelm Miklas" (Urban 1996: 13, doc. 5). Realmente Seyss-Inquart le envió para que el presidente firmase la Anschlussgesetz pero Miklas prefirió dimitir.

Las consecuencias de la unificación se empezaron a notar ya el 26 de marzo cuando se anunció la intención de crear una Viena 'germana' y Hermann Göring indicó en un mitin que con 300.000 judíos no podía considerarse 'germana' (Pauley 1992: 290). En la Universidad de Viena la depuración de estudiantes judíos había comenzado desde el triunfo de Dollfuss y la creación de Vaterländische Front en el curso 1933-1934, acelerándose drásticamente en el curso 1938-1939 (Grüttner 1995). La prohibición fue efectiva antes de iniciarse el curso en septiembre, cuando ya Menghin no era Ministro de Educación. Sin em- 
bargo fue el quien sentó las bases de su aplicación. Básicamente se trasladaba la normativa alemana que, desde 1933, establecía como máximos un $1,5 \%$ de alumnos judíos en el primer año, normalmente con un abuelo o abuela judía, y un 5\% en la facultad (Grüttner 1995: 213). Según las estadísticas de la Universidad de Viena, de los 9.180 alumnos matriculados en el primer semestre del curso 1937-1938, se bajó a 5.350 alumnos en el primero del curso 1938-1939, esto es, un descenso del $42 \%$. Por la depuración simultánea del profesorado (Heiber 1991), perdieron su trabajo unos 200 profesores por ser judíos y unos 130 por sus simpatías izquierdistas hacia socialdemócratas, comunistas y algunos católicos. Se eliminó en torno al 40\% del profesorado.

Las causas de la salida de Menghin del gobierno de Seyss-Inquart no están completamente definidas. Seguramente están vinculadas con su reducción el 31 de mayo de 1938. Según la denuncia de 25 de junio de 1945, presentó su dimisión a finales de abril de 1938, "pues aparentemente prefería ser científico antes que político" (Urban 1996: 12, doc. 3), permaneciendo menos de 2 meses (Kohl y Pérez Gollán 2002: 565). No obstante, Margarete, la mujer de Menghin, indicaba a Martínez Santa-Olalla que estuvo en el gobierno 2 meses y medio (ASO/15042 12-61946). Ello nos aproximaría al 31 de mayo (Geehr 1986: 13), cuando se produjo la citada reorganización ministerial por la que Hans Fischböck pasó de Ministro de Comercio y Trabajo a Ministro de Finanzas y Wilhelm Wolf, Ministro de Asuntos Exteriores, dejó el gobierno. En todo caso, si bien se reincorporó a la Universidad de Viena el 5 agosto de 1938, significativamente, siguió cobrando su sueldo de Ministro en reconocimiento de su ayuda en propagar los "valores culturales del Nacional-Socialismo" (Geehr 1986; Kohl y Pérez Gollán 2002: 565).

\subsection{O. Menghin como miembro del Partido Nacional-Socialista}

El 1 de mayo de 1938, Menghin, siendo Ministro de Educación, presentó su solicitud de ingreso en el NSDAP con el n. 411 (Geehr 1986: 16, n. 20; Urban 1996: 12, doc. 5). Los primeros informes al respecto se retrasaron hasta el 24 de octubre (Urban 1996: 11, doc. 2). La resolución se alargó hasta el 8 de septiembre de 1939, por haber sido miembro de la asociación católica secreta Deutschen Gemeinschaft entre 1919-1926 y de la Asociación Católica Estudiantil Rudolfina. La primera era la más problemática porque muchos de sus miembros se incorporaron a la asociación católica secreta Der weisse Turm (La Torre Blanca), existente hasta 1938 , y "No se ha podido comprobar si el solicitante también perteneció" a ella. Considerado un "hombre entre dos frentes [cuya] confianza incondicional debe ser probada aún", la solicitud no se ratificó hasta el 29 de febrero de 1940 (Geehr 1986: 24, 2003: 139, n. 35; Urban 1996: 9, 11 doc. 2, 12 doc. 4). $\mathrm{El}$ informe interno del NSDAP indicaba que era un católico nacional-socialista, partidario del Anschluss y la unificación con el Tercer Reich, que había pertenecido al Comité de los Siete de la Universidad de Viena, entonces sospechosos de filtrar información al NSDAP. Le define como un "negro nacional", porque según informes de dos Dozentenführers, miembros de la Liga Docente nazi, el Dr. Wolfram Pichler y el Dr. A. Marchett, "se le atribuye ser muy religioso y no poder sacarse la sotana negra", algo no "muy adecuado para un cargo de liderazgo" (Urban 1996: 12, doc. 4). En todo caso, figura como afiliado $n .^{\circ} 8.123 .303$ desde el 1 de julio de 1940 (Urban 1996: 9). Su capacidad de adaptación a una Alemania victoriosa se muestra en octubre de 1941 en otro informe interno del NSDAP, donde se señala que "Ahora (...) ya no se lo ve en absoluto en la iglesia" y no es un "chupacirios" (Fontán 2005: 82, doc. 7). Otro informe de febrero de 1942 advierte que "A pesar de ser muy religioso y cristiano, ya con anterioridad a la transformación no era considerado un asiduo concurrente a las iglesias" (Fontán 2005: 82, doc. 7).

Los informes del NSDAP indican sus excelentes relaciones con las principales jerarquías del Tercer Reich en Austria en febrero de 1942, siendo "una persona de total confianza, íntimo amigo del Gauleiter Dr. [Hugo] Jury y que posee un retrato del ministro del Reich, Dr. [Wilhelm] Frick" (Urban 1996: 12, doc. 4). El Dr. Hugo Jury, responsable político de la región Niederdonau-Niederösterreich dentro del NSDAP entre mayo de 1938-1945, era la principal autoridad regional del partido. Compañero de Menghin en el gobierno de Seyss-Inquart, se suicidó al final de la guerra el 8 de mayo de 1945. El abogado y doctor Wilhelm Frick, Ministro del Interior del 
Tercer Reich, entre el 20 de enero de 1933 y el 20 de agosto de 1943, se ahorcó el 16 de octubre de 1946, tras ser sentenciado en el juicio de Nuremberg.

\section{O. MENGHIN Y J. MARTÍNEZ SANTA-OLALLA}

Menghin entró en contacto con Julio Martínez Santa-Olalla en 1938. Este arqueólogo nació en Burgos el 23 de agosto de 1905. Estudió la carrera en Madrid, Barcelona y Valladolid hasta licenciarse en 1926. Con el apoyo de Hugo Obermaier, consiguió un puesto de lector de español en la Universidad de Bonn entre abril de 1927 y julio de 1931. Se doctoró en junio de 1932 con la tesis Elementos para un estudio de la cultura de los Talayots en Menorca, dirigida por Obermaier el curso 1931-1932, mientras era su Ayudante en la Cátedra de Historia Primitiva del Hombre. En 1933 entró como Profesor Auxiliar de Arqueología, Numismática, Epigrafía e Historia Primitiva del Hombre en la Universidad de Madrid. En marzo de 1936 ganó la cátedra de Historia del Arte, Arqueología y Numismática de la Universidad de Santiago de Compostela (Mederos y Escribano 2011: 115-127).

Menghin, un mes después de su dimisión, coincidió con Martinez Santa-Olalla en el Jubileo del Forchunginstitut für Kulturmorphologie (Instituto de Morfología Cultural) de Frankfurt celebrado el 29 de junio de 1938, donde el segundo asistía como representante del Gobierno de Burgos y de Falange Española (Narr 1974: 76; Gracia 2009: 292-293). Su conferencia Geist und Boden (Espíritu y Tierra), publicada en la revista quincenal Die Warte (El centinela), nos muestra al Menghin (1938) nacional-socialista. El nombre es próximo al de la principal revista femenina del NSDAP, Die Frauen Warte. Es probable que Menghin invitase a Martínez Santa-Olalla a visitar Viena, e incluso impartir una conferencia, pues durante esa estancia de 1938, a petición suya, le dedicó una fotografía en Viena, que aún conservaba en 1948: "su retrato dedicado en Viena está sobre mi mesa en el Seminario [de Historia Primitiva] en la Universidad" (ASO 20-61948). También se ha sugerido que en el mismo viaje, Martínez Santa-Olalla visitara las excavaciones de las SS en Glauberg, Haithabu y Vogelherd (ASO 1941 cv JMSO; Ortega y Quero

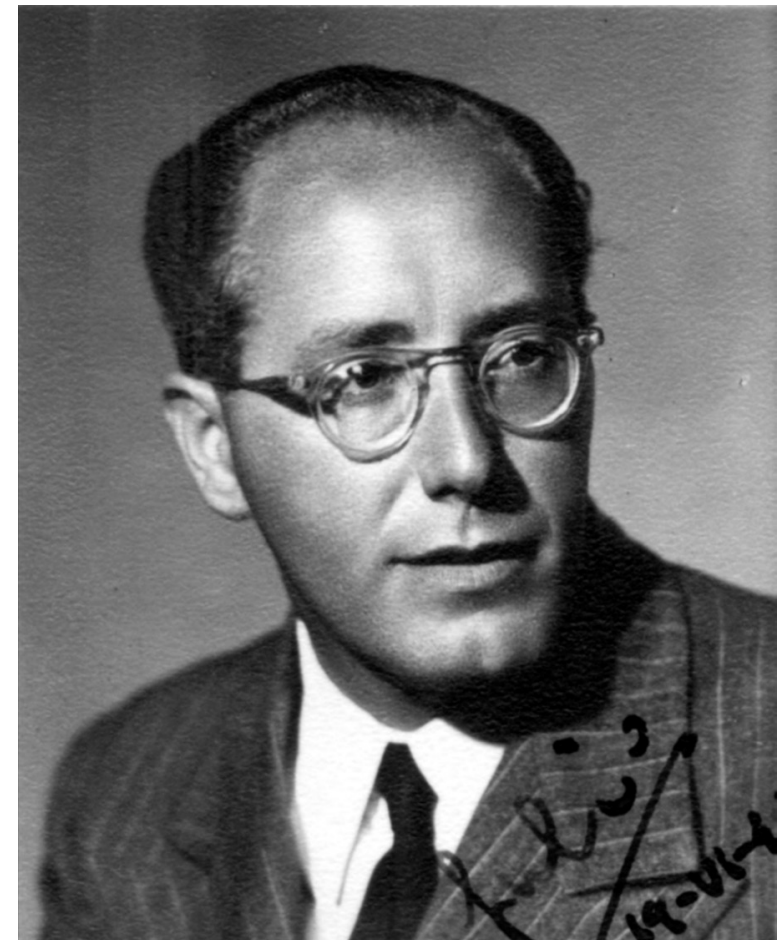

Fig. 4. Julio Martínez Santa-Olalla, Catedrático interino de Historia Primitiva del Hombre de la Universidad de Madrid entre 1939-54 y Comisario General de Excavaciones Arqueológicas entre 1939-55 (16-6-1941. Museo de San Isidro, Madrid).

2002: 202; Gracia 2009: 293). Eso implicaría una estancia significativa: Haithabu-Hedeby, que excavaba Jankuhn, es un asentamiento vikingo en la frontera con Dinamarca; el oppidum céltico de Glauberg está en Hessen, en el centro-sur de Alemania y la cueva paleolítica de Vogelherd en Württemberg, ya en el Sur. Una carta de Martínez Santa-Olalla a Pérez de Barradas (FD2005 5-91938) parece ratificarlo. Indica que regresó de Frankfurt el 12 de julio, es decir, unas dos semanas después del Jubileo y cayó enfermo varias semanas por el agotamiento del viaje (Fig. 4).

La relación entre ambos se constata más tarde en una carta de Menghin (ASO 2-10-1938) donde se muestra como nacional-socialista, ya desde el encabezado "Querido amigo y camarada", despidiéndose con un "Heil Hitler!". En ella justificaba la anexión de los Sudetes por el Führer y destacaba su habilidad al haberlo conseguido sin que estallara una guerra mundial, después del acuerdo de Munich el 30 de septiembre. 


\subsection{El viaje de O. Menghin a España en 1942}

Menghin fue invitado por el Rector de la Universidad de Barcelona desde 1941, Francisco Gómez del Campillo, y por el Director del Instituto Alemán de Cultura en Barcelona, Dr. Erich Krotz, donde el 17 de junio de 1942 dio la conferencia "La formación del pueblo egipcio a la luz de las nuevas excavaciones alemanas realizadas desde el año 1929 a 1939", publicada en Ampurias (Menghin 1942a). La presentó Almagro Basch y asistieron el Rector, los decanos, el Director de dicho Instituto y el Cónsul de Alemania (Anón. 1942: 6).

Una vez en Viena, Menghin habló con el SSObersturmführer Teniente Kurt Willvonseder, compañero suyo en el Instituto de Prehistoria, quien inmediatamente informó a Sievers que "Menghin ha traído más noticias de España que ponen al Profesor J. Martínez Santa Olalla todavía más en entredicho". El 17 de julio Menghin se entrevistó con el SS-Sturmbannführer, Comandante Herbert Jankuhn, que debía asistir a una segunda campaña de excavación en la necrópolis visigoda de Castiltierra (Fresno de Cantespino, Segovia). El 20 de julio informó al SS-Oberstrumbannführer, Teniente Coronel Wolfram Sievers, que en la primera, realizada entre agosto y septiembre de 1941 (Werner 1946: 46-47), Martínez Santa-Olalla había desplazado a Emilio Camps Cazorla y José María de Navascués, sus excavadores entre 1932-1935; carecía de influencia en el Ministerio de Educación Nacional; peligraba el apoyo que le prestaba José Luis de Arrese, Ministro Secretario General del Movimiento entre 1941-1945, lo que era infundado; García y Bellido no aceptaba viajar a Alemania, mientras lo hiciese Martínez Santa-Olalla, aunque quizá por los bombardeos que ya estaba sufriendo el país; y se sugería a Martín Almagro Basch, Luis Pericot y Antonio García-Bellido como posibles interlocutores para Das Ahnenerbe (Gracia 2008b: 15, 2009: 317-318).

Además de visitar Barcelona, se ha sugerido que Menghin se encontró en Madrid con Martínez Santa-Olalla (Schobinger 1974-75: 323). Sin embargo, esta visita no se produjo por los comentarios negativos sobre el mismo tanto de Almagro Basch, entre enero y febrero de 1942 durante una estancia en Alemania becado por la Humboldt Stiffung des Deutsches Akademisches Autauschdienst (Gracia 2008a: 141 n. 60, 2008b:
15), como de otros arqueólogos de Barcelona. Dos días después de la conferencia, el 18 de junio de 1941, Martínez Santa-Olalla informaba a Pérez de Barradas que "Menghin no viene", indicando en su diario que "probablemente por manejos de Almagro". Al día siguiente escribía, "Julio se lo tiene bien empleado, por haberle colocado en Barcelona, creyéndolo de confianza" (PB2005/1/24: 93).

\subsection{J. Martínez Santa-Olalla y el Tercer Reich}

Trabajos previos han mostrado distintos aspectos de las relaciones de Martínez Santa-Olalla con la Alemania nazi, y en particular, con Himmler y las SS Ahnenerbe (Gracia 2008a, 2009: 291-334; Mederos y Escribano 2011). Pero un dato importante que pone de manifiesto su ideología es la continuidad y firmeza de su apoyo al Tercer Reich hasta el final de la Segunda Guerra Mundial.

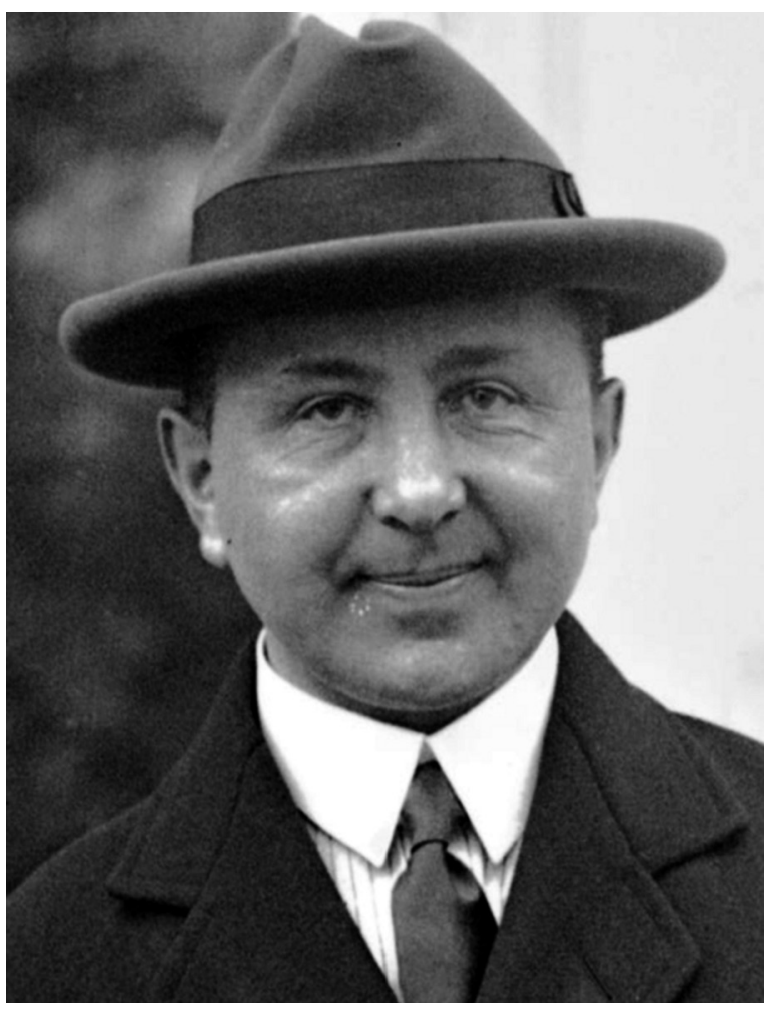

Fig. 5. Hans Heinrich Dieckhoff, Embajador del Tercer Reich en España entre abril de 1943 y septiembre de 1944 y buen amigo de Julio Martínez Santa-Olalla (1924. Library of Congress, Washington). 
Dos acontecimientos muestran su relación muy estrecha con Hans-Heinrich Dieckhoff, el embajador alemán en Madrid, entre el 30 de abril de 1943 y el 2 de septiembre de 1944. Este desde 1941 era miembro del NSDAP y estaba casado con la hermana del Ministro de Asuntos Exteriores, Joachim von Ribbentrop (Taschka 2006) (Fig. 5). El 11 de marzo de 1944 el embajador presidió el acto en homenaje de Martínez SantaOlalla en el quinto aniversario de la creación de la Comisaría General de Excavaciones Arqueológicas (Martínez Santa-Olalla 1945; Díaz-Andreu y Ramírez 2001), a pesar de la presencia de otras altas autoridades como el Director General de Bellas Artes, Marqués de Lozoya, o el Rector de la Universidad Central de Madrid, Pío Zabala (Arriba 12-III-1944) (1). El 29 de marzo de 1944 también presidió la conferencia madrileña de Martínez Santa-Olalla sobre "La arqueología aérea en España" en la Sociedad Española de Antropología, Etnografía y Prehistoria (SEAEP 293-1944; Anón. 1944: 14). Pero el mejor testimonio de su ideología nacional-socialista es la carta que le remitió en mayo de 1945 al embajador con motivo de la muerte de Hitler (ASO 2-5-1945): "Señor Embajador: Ante la inmensa desgracia de la muerte heroica y gloriosa del Führer Adolf Hitler, hago llegar a V. mi condolencia más profunda y la reiteración del agradecimiento que como español debo a Hitler juntamente con el Duce Benito Mussolini, ya que si puedo escribir esta carta a ellos lo debo, pues su ayuda nos salvó momentáneamente del comunismo.

Ha sonado en Europa y el mundo la hora del comunismo. Triunfa Stalin gracias a la traición anglosajona a las esencias de una civilización multimilenaria. Las hordas soviéticas triunfarán en todos y en todas partes. Un día no lejano sonará la liberación de Europa y con ella del mundo, y entonces Hitler y Mussolini renacerán a una gloria universal y apoteósica. Los que podamos o puedan ver este momento admirarán la fecundidad de unos genios y unas fórmulas de vida civilizada y revolucionaria que habrán triunfado de la revolución negativa rusa. Que Dios haya acogido en su seno a Hitler, Mártir de Europa y de nuestra civilización. HEIL HITLER!!!!!”.

(1) Diario Arriba (Prensa del Movimiento, Madrid) 12-III1944. Consultado como recorte sin paginar en el archivo del Museo de San Isidro (Madrid). El diario no está digitalizado en ese intervalo de años.

\subsection{Detención, encarcelamiento de O. Menghin y huida a Argentina}

Menghin, inteligente y previsor, seguramente no veía clara la evolución de la guerra por lo que, probablemente ya avanzado 1943, trató de mejorar su conocimiento del idioma español para emigrar al extranjero. Por primera vez en enero de 1944 (ASO 25-1-1944), envió una carta a Martínez Santa-Olalla con varias frases en castellano y sin utilizar ninguna vinculación militante de partido, ni en el encabezado, "Querido amigo", ni al final, "A sus órdenes". En la fecha de la carta, la situación militar había cambiado completamente. Berlín era constantemente bombardeada, como otras ciudades alemanas; el 4 de enero los rusos habían alcanzado la antigua frontera entre Polonia y la URSS; el 22 de enero los aliados desembarcaban en las playas de Anzio al Sur de Roma y el 24 de enero los rusos finalizaban el sitio de Leningrado.

Uno de los primeros colaboradores de Menghin en Argentina, Rex González (2008: 26) ha indicado que, aunque no hablaba del tema, alguna vez comentó que Hitler "era un loco". A Juan Schobinger (2008: 4) una vez le mencionó el enorme error que fue entrar en política, una porquería (schweinerei). Como señala Schobinger (1958-59: 11), tampoco le preguntaban: “¿Por qué había venido a la Argentina? No me interesaba mayormente, y no interesa hoy día en que las dificultades de su país de origen han quedado superadas y relegadas al olvido". La información que trasmitió Menghin no era del todo veraz. Según Schobinger (2008: 4), "El renuncia el mismo día que los alemanes entraron en Austria en conjunto con otros correligionarios de su mismo partido, algo que me corroboró su hija, la Dra. Schwarz (...) como miembro del partido Católico". Sabemos que, al contrario, fue nombrado ministro.

La opinión de Menghin sobre su colega y profesor de Etnología en la Universidad de Graz, Hugo Bernatzik, parece reflejar su propia evolución, "Bernatzik fue un gran Nazi en los estadios primeros del Anschluss, pero, como muchos, cambió sus opiniones hacia el fin de la guerra. Pero fue siempre muy moderado, y no ha persecutado a nadie según mi saber" (ASO 26-3-1949).

Antes de acabar la Segunda Guerra Mundial el 25 de junio de 1945, Menghin abandonó la Universidad de Viena en marzo de 1945 ante el

Trab. prehist., 71, N. ${ }^{\circ}$ 2, julio-diciembre 2014, pp. 199-220, ISSN: 0082-5638

doi: $10.3989 /$ tp.2014.12131 
avance soviético pidiendo permiso para permanecer en Mattsee, Salzburgo (Urban 1996: 9), tras la ocupación de Budapest en febrero. El 25 de junio de 1945 se presentó una denuncia contra Menghin señalando: "Su pronto alejamiento de este gobierno [de Seyss-Inquart] así como el aplazamiento de su solicitud de afiliación al partido nazi [entre 1938-1940], no podrán eximirlo de la adhesión al partido nazi en un cargo de mucha influencia" (Urban 1996: 12, doc. 3). No obstante, ya previamente en mayo de 1945 se había producido su detención por los norteamericanos en Salzsburgo. Hasta febrero de 1947 permaneció internado en los campos de prisioneros en Ludwigsburg (Baden-Wurtemberg) y Darmstadt (Hesse), en Alemania, impartiendo allí un centenar de conferencias (Narr 1974: 73, 75; Fontán 2005: 84 doc. 9; ASO 8-9-1948). En este período, su mujer Margarete escribió a Martínez Santa-Olalla dos cartas, el 12 de junio y el 26 de agosto de 1946, desde Mattsee en Salzburgo (ASO 15.042 y 15.043).

La modificación en Austria de las leyes de desnazificación, entnazifiziert, en 1947 favoreció la salida de muchos nacional-socialistas. Fueron liberadas de los campos de prisioneros unas 86.000 personas: 44.244 en la zona americana, el $46 \%$ de 95.250 prisioneros (Schenk 2001). En Alemania y Austria, lo fundamental fue separar los miembros del NSDAP que habían desempeñado cargos orgánicos, 42.000 "contaminados" y aquellos sin antecedentes significativos, 495.000 "ligeramente contaminados" (Blaschitz 2002: n. 45). Los segundos fueron amnistiados para favorecer la recuperación económica y contribuir al establecimiento de un sistema democrático.

Menghin conocía bien la región del Tirol austriaco, no solo por su nacimiento, sino también por haber realizado allí trabajos de campo (Menghin 1939, 1942b, 1949b). Como otros refugiados con antecedentes nazis, utilizó la población de Nauders, en el distrito de Landeck, junto a la frontera italiana y suiza, para huir. Detenido por la policía italiana, fue extraditado y devuelto a Nauders. Volvió a escapar el 30 de marzo de 1948, según el informe policial del 31 de mayo (Blaschitz 2002: n. 19), pero ese mismo mes ya había partido hacia Argentina (Narr 1974: 73).

La huida le permitía superar los requisitos de la oficina de emigración austriaca para recibir un pasaporte: no ser personal laboral esencial para la economía austriaca, tener pagado el billete de barco en dólares americanos, aunque oficialmente no era posible obtener autorización para conseguir moneda extranjera, y tener un pasaporte válido y un contrato de trabajo antes de aprobarse el visado (Blaschitz 2002: n. 10). Esta huida, basada en documentos policiales, no concuerda con la versión de Alonso del Real (1991: 166), secretario de Martínez Santa-Olalla en la Comisaría General de Excavaciones y catedrático de Prehistoria e Historia Universal Antigua y Media de la Universidad de Santiago de Compostela desde 1955. Según su versión, "Vere Gordon Childe le salvó la vida a Menghin". Se enteró que estaba detenido en un campo de prisioneros de los soviéticos, y tras llamar a Rusia habría conseguido que lo liberasen. La información a Gordon Childe pudo llegar quizás a través de carta de Martínez Santa-Olalla, que estaba informado por Margarete Menghin. Quizás Alonso del Real la transcribiera como secretario, pues indica "tuve alguna intervención en ese asunto". Sin embargo, Menghin estaba detenido en zona norteamericana, y si hubo gestiones fueron realmente con el gobierno americano. En todo caso, su liberación parece coincidir más con la de los "ligeramente contaminados", puestos en libertad en 1947. Por otra parte, Rex González (2008: 26) comenta que a Menghin "la sola mención de Gordon Childe le producía una alergia aguda", algo incomprensible si hubiese propiciado su liberación.

Debe tenerse en cuenta que al final de la Primera Guerra Mundial, al entregar el Imperio Austro-Húngaro los territorios meridionales del Tirol, la ciudad de nacimiento de Menghin, Meran, pasó a ser territorio italiano como Merano (Bolzano, Trentino-Alto Adige). Es decir, que formalmente Menghin había nacido en Italia y seguramente viajó con pasaporte italiano.

El 27 de marzo de 1945, Argentina había declarado la guerra a las potencias del Eje. Sin embargo, como señaló Perón en 1970, "Les hicimos saber a los alemanes que les íbamos a declarar la guerra para salvar miles de vidas. Intercambiamos mensajes con ellos a través de Suiza y España. Franco entendió de inmediato nuestra intención, y nos ayudó. Los alemanes también se mostraron de acuerdo" (Martínez 1996: 183). Según Perón, al finalizar la guerra, "En Nuremberg, se estaba realizando entonces algo que yo, a título personal, juzgaba como una infamia y como una funesta lección para el futuro de la humanidad. Y no solo yo, sino todo el pueblo argentino 
(...) Ahora estamos dándonos cuenta de que [los aliados] merecían haber perdido la guerra" (Luca de Tena et al. 1976: 85-86).

Para trasladarse a Argentina desde Italia, Menghin dispuso de una invitación del gobierno argentino (Blaschitz 2002: n. 35). José Imbelloni, médico y antropólogo italiano nacionalizado argentino, la gestionó por su excelente concepto del trabajo de Menghin. Le comentó a Schobinger (1958-59: 11) que la Weltgeschichte der Steinzeit (Menghin 1931) era "un libro magistral (...) escrito con filosofía". Le había conocido "de su visita en Viena hace más de 20 años" (ASO 247-1948).

Oswald Menghin pudo viajar a Argentina en abril, quizás para impartir algún curso o conferencias, pues a inicios de mayo de 1948 obtuvo su carnet de identidad, y meses después fue nombrado Profesor extraordinario contratado en el Museo Etnográfico de la Universidad de Buenos Aires, ya con 60 años (Narr 1974: 73; Schobinger 1974-75: 324; Kohl y Pérez Gollán 2002: 566 n. 14). Se ha señalado que Menghin en apenas dos semanas obtuvo un contrato a través de Imbelloni (Kohl y Pérez Gollán 2002: 566 n. 14), pero este no se produjo hasta el 1 de septiembre de 1948, unos 4 meses y medio después de su llegada, según indicó el propio Menghin a Martínez Santa-Olalla, "Desde el 1. de se[p]t[iembre]. soy profesor contratado de la Universidad de B[ueno] s. A[ire]s. Trabajo en el Museo Etnográfico, cuyo director es Dr. Imbelloni" (ASO 22-12-1948). Por otra parte, Imbelloni sólo escribió a Martínez Santa-Olalla informándole de la presencia en Argentina e incorporación a la Universidad de Buenos Aires de Menghin cuando esta se materializó en septiembre (ASO 28-9-48). Tenía un salario de "1650 pesos neto, que es mucho en tiempos y bajo condiciones normales. Pero la inflación paraliza un poco el efecto, siendo mucho caro muebles, tejidos, etc." (ASO 25-2-1949). Schobinger (2008: 6) da la referencia más ajustada a la realidad: Menghin "empezó trabajando con un pequeño contrato que le consiguió Imbelloni para investigar en el Museo Etnográfico".

Después de la victoria de Juan Domingo Perón en las elecciones generales del 24 de febrero de 1946 , la coyuntura para contratar nuevo profesorado era favorable. Desde el 30 de abril el gobierno intervino en las universidades, designándose para la de Buenos Aires un Vicerrector Interventor, el arquitecto Julio Otaola, nombrado luego rector entre 1949-1952. Se introdujo la elección del Rector por el gobierno y la del Decano solo por el claustro de profesores, limitándose la autonomía del profesorado, en docencia e investigación. El cese de 423 profesores y la dimisión solidaria de otros 823 (Soprano 2009: 65) permitió la entrada de nuevos docentes. A ello se sumó el intento frustrado de Imbelloni de crear una licenciatura en Ciencias Antropológicas a finales de los años cuarenta, para la cual necesitaba nuevos profesores (Guber y Visacovsky 2006: 6).

La huida de Menghin de Austria fue planificada, lo que le permitió empaquetar la mayor parte de su colección de libros, "tuve que pagar todo el transporte de los cajones de los míos, conteniendo muchos libros y mis manuscritos científicos. Felizmente tuve un amigo alemán el cual me prestó la suma de 2.500 pesos para este fin. Otros 2.500 pesos debo a una amiga en los USA, etc." (ASO 25-2-1949).

Según su correspondencia, primero residió en una habitación, junto a Hugo Dolezalek, Oficina Tracción, Avenida Maipú, 4, Buenos Aires (ASO 20-6-1948). De allí pasó a Sertres 476, Buenos Aires (ASO 27-8-1948). Finalmente, ya con su familia en Buenos Aires, se comprometieron a darle una vivienda próxima a la estación a partir de abril de 1949, mientras que el yerno, su hija y su nieto consiguieron "un buen departamento en combinación con su trabajo" (ASO 24-2-1949). Finalmente, en diciembre, consiguió una vivienda estable, "una casa relativamente barata que me satisface (...) teniendo un jardín que recuerda nuestra casa en Viena y la posibilidad de arreglar mis libros y papeles. Pude salvar mucho, como veo ahora, desempaquetando mis cajones" (ASO 15-1-1950).

El 15 de junio de 1948, Menghin, aún sin su familia, escribió desde Buenas Aires una carta a Martínez Santa-Olalla (ASO 15-6-1948), completamente redactada en castellano, indicándole que "Perdone mi Castellano aun defectuoso. Hago muchos esfuerzos de aprenderlo en el más breve tiempo posible". Señalaba "Aún no tengo una colocación, sino voy buscando un puesto en un museo o una universidad". Sus peticiones más importantes eran "si Usted pudiera proporcionarme una recomendación al embajador español en la Argentina”, “¿tiene Ud. relaciones con personas en Argentina, las cuales (...) puedan ayudarme en mis esfuerzos de hallar una colocación 
satisfactoria?". Asume que deberá "cambiar algo el estilo de mi trabajo científico; por falta de la literatura no podré continuar de escribir artículos de carácter universal (...) En adelante consagraré mi consideración particular a la prehistoria del Mediterráneo, incluido la España (...) Naturalmente espero también de dar con ocasiones de participar en las investigaciones de la prehistoria sudamericana".

La rápida respuesta de Martínez Santa-Olalla (ASO 20-6-1948) ofrecía apoyo incondicional indicándole que "le enviaré a V. una carta para la Sra. de Perón, otra para el Embajador de España, otra para el Prof. Sánchez Albornoz, catedrático de nuestra Facultad de Madrid, expatriado, un gran caballero y un gran universitario, que es catedrático en Buenos Aires, otra para el Prof. Imbelloni de la Universidad de Buenos Aires (el hombre de más talento en el campo de la etnología de América española) y otra para el Prof. Márquez Miranda de la Universidad y Museo de La Plata (alumno y doctorando mío en Madrid antes de nuestra Guerra)".

Un mes después, Menghin volvió a escribirle (ASO 24-7-1948) avisándole que el "Prof. Miranda ya no está en La Plata". Ello pone en evidencia que Martínez Santa-Olalla desconocía que Márquez Miranda había sido expulsado en enero de 1947 de la Universidad de Buenos Aires y en febrero de la Universidad Nacional de la Plata, aunque mantuvo la Cátedra de Historia en el Colegio Nacional de Buenos Aires, impartiendo clases de Antiguo Oriente. Había sido Profesor titular de Prehistoria y Arqueología Americanas en la Universidad de la Plata desde 1933 hasta 1947, a la vez que entre 1939-1947 obtuvo el puesto de Profesor adjunto en Prehistoria y Arqueología Americana en la Facultad y Museo Etnográfico de la Universidad de Buenos Aires (Lafon 1967: 16-17; Schobinger 2008: 10; Soprano 2009: 68-69). Se había doctorado en la Universidad Central de Madrid en 1936 sobre Arqueología Argentina, bajo la dirección de Obermaier, en cuyo tribunal de tesis participó Martínez Santa-Olalla, impartiendo en febrero de 1936 un curso sobre Arqueología del Noroeste argentino.

El contacto más valioso parece haber sido el Embajador de España en Argentina entre 19471950, el jonsista y después monárquico, José María de Areilza y Martínez de Rodas, III Conde de Rodas, IV Conde consorte de Motrico y Conse- jero Nacional de Movimiento desde 1946. Bajo la referencia de "confidencial" le señalaba que "ya tengo buenas relaciones con el Embajador de España, que es una personalidad verdaderamente excelente" y "me prometió su ayuda en todos los asuntos" pues "me encontré ante grandes dificultades en este país" (ASO 24-7-1948). La marcha de Areilza de Argentina para dedicarse a sus negocios fue sentida mucho por Menghin, "me enteré con gran duelo que el Conde de Areilza no regresará a la Argentina. Espero que es llamado a un puesto aún más responsable (EEUU?). Es hombre de la más alta cultura y inteligencia al cual agradezco mucho" (ASO 15-1-1950) y "Quedará inolvidable la ayuda que me prestó" (MAC 15-1-1950). Areilza, como pronosticaba Menghin, fue nombrado embajador en los Estados Unidos entre 1954 y 1960.

Otro contacto importante fue Claudio Sánchez-Albornoz y Menduiña, catedrático de Historia Antigua y Media de España de la Universidad de Madrid hasta 1939, que huyó a Argentina desde Francia cuando los alemanes conquistaron el país. Le califica de "una persona muy impresionante". La buena relación entre ambos no sólo se refleja en la inmediata colaboración desde 1948 en los Cuadernos de Historia de España, que dirigía Sánchez Albornoz (Menghin 1948b), sino que enterado Menghin que su hijo, Nicolás Sánchez Albornoz y Aboín, estaba encarcelado en España, pidió la mediación de Martínez SantaOlalla, en un gesto que le honra, "su hijo, que parece de haber cometido una grande tontería política. No es posible a Ud. de hacer algo para su liberación? Me falta cada posibilidad de juzgar su delito. Pero repito la oración que escribió Ud. en su carta. Yo también sufrí y me siento más cerca de los que sufren".

Sin embargo, un mes después la situación cambió completamente. Nicolás Sánchez Albornoz había sido detenido con otros 13 estudiantes por tratar de reconstruir la FUE, Federación Universitaria Escolar. Encarcelado en Alcalá de Henares y Carabanchel, sufrió Consejo de Guerra el 12 de diciembre de 1947 y fue condenado a 6 años de trabajos forzados, siendo destinado al Destacamento Penal de Cuelgamuros, actual Valle de los Caídos. Allí, después de trabajos forzosos durante 5 meses, consiguió huir con el novelista Manuel Lamana en agosto de 1948. La huida fue preparada por el antropólogo Francisco Benet, miembro de la FUE exiliado en Francia y 
hermano del novelista Juan Benet, quien envió a recogerlos a una estudiante norteamericana, Bárbara Probst Solomon, entonces residente en París, que los trasladó en automóvil hasta Cataluña, cerca de la frontera francesa, la cual atravesaron a pie durante 3 días. Después de unos meses residiendo en Francia, se embarcó para Argentina (Sánchez-Albornoz 1976) (2). Cuando le contestó Martínez Santa-Olalla en septiembre, le pidió más información sobre el hijo de Sánchez-Albornoz, desconociendo que ya se había fugado del Valle de los Caídos, "Del asunto del hijo que en realidad no conozco me gustaría que el propio padre me dijese si cree puedo hacer algo en que habría de consistir" (ASO 28-9-1948).

En cambio, Menghin se mostraba muy molesto por la falta de apoyos de los arqueólogos suizos, suecos e ingleses. "Particularmente la gente de la Suiza se portó muy antipático. Los colegas de Suecia no me dan contestación tras mi liberación y hasta mi antiguo amigo Crawford (...) respondió bastante reservado", señalando con patente escepticismo, "Si consigo a tener nuevos éxitos en el mundo nuevo, hallaré sin duda nuevos amigos, pero de que valor?" (ASO 24-71948). Tampoco tuvo respuesta de la italiana Pía Laviosa Zambotti, "no me ha contestado a mi carta que le envié a ella de Buenos Aires" (ASO 8-9-1948) o a veces de Luis Pericot, "No oigo nada de Pericot respecto a varias cartas que le remití. Está enfermo?" (MAC 20-8-1954).

No había recibido aún la carta para Eva Perón y se lo recordaba, "Sobremanera valiosa sería para mi la prometida recomendación a la Sra. de Perón. Es la dama a la cual admiro más (...) Usaría esta recomendación solamente en caso de extrema necesidad para no molestarla" (ASO 247-1948). Su objetivo no era un puesto de trabajo, sino buscar alojamiento pues el 27 de agosto informaba que "muy probable llegarán mi esposa, mi hija y mi yerno a medi[ad]os de septiembre a Buenos Aires (...). Especialmente la cuestión del alojamiento es muy difícil acá. Sería extrema[da] mente provechoso para mi, si Ud. pudiera enviarme ahora una recomendación a la Sra. P[erón]., porque el gobierno dispone de aposentos. El

(2) Sánchez-Albornoz y Aboín, N. 1976: "La doble historia de Nicolás Sánchez Albornoz. "Mi fuga del Valle de los Caídos fue organizada por la FUE". Diario El País, Madrid 27 de junio de 1976 elpais.com/diario/1976/06/27/sociedad/204674436 850215. html, consulta 5-XI-2014. asunto es tanto más urgente, porque mi hija dará a luz en medios de octubre" (ASO 27-8-1948), confirmado poco después, "Pude arreglar que mi esposa, mi hija y mi yerno vienen a Buenos Aires. Ya se hallan en el buque, los espero el 18 de se[p] tiembre" (ASO 8-9-1948). "Llegaron a mediados de se[p]tiembre. Mi hija ha dado a luz aquí el día 24 de nov[iembre]. un varón, así que fue [soy] abuelo de un verdadero argentino" (ASO 22-121948).

En un informe confidencial del NSDAP de octubre de 1938, se indica que Menghin estaba casado con Margarete Ponzaimer, nacida el 31 de julio de 1894, 6 años menor que él. Tenían dos hijos, Othmar de 18 años y Rotgard de 15 años (Fontán 2005: 71 doc. 2, 73 doc. 3), que debe ser una mala transcripción por Fontán del nombre de su hija Botraud. Su hijo estaba trabajando en la Universidad como "asistente del prof. Franz en Innsbruck" (MAC 14-3-1951).

Según los archivos de emigración argentinos, una Margarita Menghin, con pasaporte italiano, pero nacimiento en Dürnkrut (Gänserndorf, Baja Austria), en la frontera con Chequia, embarcó en Génova en el barco Santa Fe en dirección a Buenos Aires. Parece tratarse de la mujer de Oswald Menghin. Junto a ella vino su hija, nacida en Viena, Botraud Menghin de Schwartz, que tendría 25 años en 1948 y usaba el apellido de su marido.

La carta a Eva Perón se retrasó por la ausencia de Martínez Santa-Olalla de Madrid, hasta fines de septiembre. "Adjunta la carta para la Sra. de Perón (...) dado el modo de ser de ella es sencillamente pedir audiencia y presentarla la carta, que tal vez a V. germano le parezca de un lirismo raro..." (ASO 28-9-1948). Ya Martínez Santa-Olalla había escrito previamente a Eva Perón solicitándole apoyo para otra persona, "la carta para la Sra. de Perón (...) en la misma que yo aconsejé a un compañero, ha tenido éxito fulminante para cosa análoga" (ASO 31-121948). Sin embargo, Menghin no tuvo necesidad de utilizarla, "Yo prometía Ud. entonces usarla solamente en el caso de absoluta necesidad. No ha sucedido esto, porque tuve siempre ciertas perspectivas de obtener un departamento" (ASO 25-2-1949).

Un nuevo apoyo le llegó con el traslado durante el curso 1948-1949 de Antonio Tovar Llorente a la Universidad de Buenos Aires como profesor de griego. Había sido Subsecretario de 
Prensa y Propaganda del Ministerio de Gobernación a las órdenes de Serrano Suñer entre 19401941 (Mederos 2012b: 208-211). En 1942 obtuvo la cátedra de Latín de la Universidad de Salamanca. "Estoy muy feliz que Prof. Tovar ha llegado en Buenos Aires. Falta aquí un lingüista. No me re[c]ordé, que Tovar estuvo en Viena durante la guerra y que he presenciado su conferencia en la soc[iedad]. lingüística. Pero él se recordó bien de mí. Habla excelentemente alemán, así que puedo conversar con él sobre cuestiones, que aún no puedo expresar en castellano" (ASO 18-9-1948). Tovar tradujo uno de los primeros trabajos en Argentina de Menghin, una reseña del tomo I de la Historia de España de Menéndez Pidal (Menghin 1948b) y sintió mucho su marcha, "nos abandonó Tovar, con el cual nos reunió una relación muy cordial" (MAC 15-1-1950).

Ese año Menghin reseñó el principal libro de Martínez Santa-Olalla (1946), el Esquema paletnológico de la Península Hispánica. Lo consideraba "una de las más hermosas descripciones del pasado prehistórico de un país europeo" (Menghin 1948a: 300), pero incorporaba significativas críticas. No dudó en llamarlo "opúsculo", no libro, pues se trataba de un artículo ampliado (Martínez Santa-Olalla 1941), distanciándose de varios de sus argumentos. Califica de lapsus calami el origen europeo oriental del Magdaleniense por incomprensible. Avisa que los propios términos del Neolítico ibero-sahariano, "ya anticipan distintas ideas sobre el neolítico africano y por eso parecen algo peligrosas". Rechaza su definición del Eneolítico como Bronce Mediterráneo I, prefiriendo el antiguo nombre "mientras no hay certeza de que exista verdadero bronce conteniendo estaño en este tiempo". Acepta que, en la invasión indoeuropea que vincula con el Bronce [Final] Atlántico, "España ha obtenido sus primeros inmigrantes indoeuropeos", pero advierte que "sus centros de formación primitivos en Europa central y occidental reclaman un estudio concluyente y por eso todas las conclusiones basadas en este material tienen solo un valor condicional". Es interesante que Menghin (1948b: 210) atribuya la prueba de esta influencia indoeuropea a Almagro Basch (1940), por su trabajo sobre el depósito metálico de la Ría de Huelva, un "brillante análisis" donde se aprecia "con plena claridad: el predominio lo logra en España la influencia del centro y del occidente de Europa; comienza la indoeuropeización de la Península".
También retomó su investigación sobre el Tumbiense africano (Menghin 1925). Martínez Santa-Olalla le indicaba "también nosotros hemos encontrado Tumbiense en Guinea continental española; lo hemos hallado en el Sahara Occidental (en Río de Oro) y también en Tánger" (ASO 21-10-1949) y le pidió un artículo para un número de 1949 de los Cuadernos de Historia Primitiva dedicado solo a África (ASO 9-31950). Pero al final prefirió publicarlo en la nueva revista Runa de Imbelloni (Menghin 1949a).

A inicios de 1950, Menghin solicitó un pasaporte en la embajada austriaca de Buenos Aires. El embajador notificó al Ministerio de Asuntos Exteriores que "durante su estancia en Buenos Aires su conducta ha sido impecable y su actitud hacia la República Austriaca puede ser vista como positiva" (Blaschitz 2002: n. 66 y 70). Informado el Fiscal del Distrito de Viena no consideró a Menghin una "prioridad", ya que solo había sido ministro durante " 6 semanas". E1 5 de abril decidió no intervenir por los elevados "costes de su extradición", pues "hay suficientes razones para esperar que Menghin será detenido cuando viaje a Austria" (Blaschitz 2002: n. 49). Este dato contradice la afirmación de Alonso del Real (1991: 169) de que la amistad de Margarete, esposa de Menghin, con Eva Perón evitó los intentos de extraditarlo. La amistad es posible que surgiera, pero después, ya que Menghin no necesitó utilizar la recomendación para Eva Perón de Martínez Santa-Olalla. Sí existía una amistad de Imbelloni con Perón, quien le redactó el prólogo al libro Toponimia patagónica de etimología araucana (Perón 1950).

\section{CONCLUSIONES}

A veces, al presentarse sin suficiente contextualización la trayectoria científica y política de Menghin, autores como Demoule (2002: 576) o Junker (2002: 578) se han preguntado por la necesidad de Menghin de emigrar a Argentina cuando su cargo de ministro había sido tan breve. También se ha indicado que Menghin no estuvo afiliado al NSDAP (Kohl y Pérez Gollán 2002: 561; Politis 2002: 580; Guber y Visacovsky 2006: 10-11), lo que no deja de extrañar cuando ya se había publicado hasta su número de afiliación (Urban 1996: 9). Títulos como el de Fontán (2005) sintetizan una interpretación opuesta, 
Oswald Menghin: ciencia y nazismo. El antisemitismo como imperativo moral, que sería supuestamente una constante en su obra científica. Pero, cuando esta se lee, la afirmación resulta excesiva. Según Politis (2002: 581) "no estuvo envuelto en una cruzada contra los judíos como a algunos les gusta presentarle".

Oswald Menghin, Catedrático de Prehistoria del Hombre de la Universidad de Viena entre 1922-1945, fue desde muy joven partidario de la unidad con Alemania. Al menos desde 1923 ya simpatizaba con ideas del NSDAP contrarias a la mezcla racial entre arios y judíos. Es evidente su radicalización durante su etapa como Catedrático-Residente en la Universidad de Fouad en El Cairo entre 1930-1933, mientras excavaba en Merimde-Beni Salâme con Hermann Junker, miembro del NSDAP, Catedrático de Egiptología de la Universidad de Viena entre 1912-1929 y desde entonces Director del Instituto Arqueológico Alemán de El Cairo. En este período redactó su libro Geist und Blut (Menghin 1934a) en el cual destaca el capítulo Die wissenschaftlichen Grundlagen der Judenfrage. Sobre este tema impartió una conferencia en 1933, en la delegación del NSDAP en El Cairo. Evidentemente no lo escribió por ser miembro del aparato de propaganda de un partido, sino por convencimiento.

$\mathrm{Su}$ etapa como Rector en el curso 1935-1936 le catapultó a la política. No solo mostró sus simpatías por el NSDAP, en uno de cuyos informes de 1941 se indicaba que "era tratado de 'nazi' en la universidad", sino que al dejar el rectorado entre julio de 1936 y julio 1937 se incorporó al consejo directivo del partido fascista austriaco, Vaterländische Front. El 11 de marzo de 1938 Hitler ordenó la invasión de Austria. Poco más de una hora después Arthur Seyss-Inquart era nombrado nuevo Canciller y elegía a Oswald Menghin como Ministro de Educación. Permaneció en el cargo hasta el 31 de mayo o inicios de junio. El 1 de mayo de 1938 solicitó su ingreso al NSDAP, pero su pertenencia a organizaciones católicas demoró su tramitación hasta ser aceptado el 1 de junio de 1940 con el número de afiliación, 8.123.303.

Hasta la Guerra Civil, su referente en España había sido el paleolitista Hugo Obermaier, licenciado en 1904 y habilitado en 1908 en Viena. Autor del manual más influyente sobre Paleolítico (Obermaier 1912) obtuvo la cátedra de Historia Primitiva del Hombre en la Universidad Cen- tral de Madrid en 1922 (Mederos 2010-11: 246-249), a la vez que Menghin era nombrado ordentlicher Professor de Urgeschichte des Menschen en su antigua universidad.

Su manual "Historia Universal de la Edad de la Piedra" (Menghin 1931), que abarcaba desde el Paleolítico hasta el Calcolítico, lo convirtió en un prehistoriador muy influyente en el ámbito germano y filogermano. Como comentaba Almagro Basch, cuando era becario en Viena, "aquí el libro de Menghin es la 'Biblia" (ASO/6-5 11-121935 p. 3). Almagro Basch (1941: 158) declara la elevada consideración que tenía de Menghin, "de todos los hombres de la Gran Alemania que cultivan la arqueología prehistórica el de más elevada visión" y su libro "la más ágil de las grandes síntesis (tal vez la mayor y mejor) de la Prehistoria mundial", lo que no le impidió criticar la reedición de 1941 por falta de actualización.

La forma de dirigir las revistas de Martínez Santa-Olalla (Anuario de Prehistoria Madrileña durante la primera mitad de los 1930) o Almagro Basch (Ampurias desde inicios de los 1940) no puede entenderse sin valorar la dirección de Menghin del Wiener Praehistorische Zeitschrift entre 1914-43, y su particular cuidado en las reseñas de libros, noticiario, etc.

La gran influencia de Menghin en la arqueología española se debe, no obstante, al papel que asignaba a Egipto en la difusión del Neolítico Final y Calcolítico hacia Europa, siguiendo una ruta norteafricana y penetrando por la Península Ibérica. Sus cuatro campañas con Junker en Merimde-Beni Salâme entre 1928-1932 y las dos con Amer en Maadi entre 1930-1932 fueron seguidas con gran interés. Presentó los resultados de estas excavaciones en el I Congreso de Ciencias Prehistóricas y Protohistóricas, en la comunicación El asentamiento neolítico de Beni-Salame y su importancia para el desarrollo del Neolítico en Europa Occidental (Menghin 1934b) y más en detalle para la Península Ibérica en un artículo remitido en enero de 1939 a la Corona de Estudios que la Sociedad Española de Antropología, Etnología y Prehistoria dedica a sus mártires (Menghin 1941).

Fechaba Maadi entre el 3400-3200 a.C. y la consideraba la posible capital del Delta oriental. Representaba un cambio significativo frente a la fase precedente de Merimde-Beni Salâme, al desaparecer los enterramientos de la zona de habitación, a la vez que se documentaban los primeros 
útiles de cobre, vasos de piedra y domesticación del asno (Menghin 1942a: 34-39). Desde su punto de vista, la cultura de Maadi, que había excavado en el Delta de Nilo, y su contemporánea Nagada II, eran el origen de la punta de flecha con pedúnculo y talla bifacial que se extendía por el Norte de África y alcanzaba la Península Ibérica. Relacionaba también el peine de marfil de Los Millares con Nagada (Menghin 1941: 179180). Situaba el contacto más evidente coetáneo con el Imperio Antiguo (Dinastías III y IV, 28002500 a.C.), al que hacía contemporáneo de la Cultura de Almería, proponiendo un origen egipcio de los sepulcros redondos, pues "los megalitos no son otra cosa que un reflejo de la magnificencia egipcia en formas más primitivas". Egipto sería también el vehículo trasmisor de la metalurgia del cobre y del oro o de las cerámicas de almacenamiento con cuello tipo El Garcel (Almería) (Menghin 1941: 180-181).

Exiliado Obermaier al estallar la Guerra Civil en 1936, Martínez Santa-Olalla y Menghin pasaron a tener una relación personal más directa a partir del Jubileo del Forchunginstitut für Kulturmorphologie de Frankfurt celebrado en junio de 1938. Martínez Santa-Olalla asistió como único arqueólogo español representante del Gobierno de Burgos y de Falange Española (Narr 1974: 76; Gracia 2009: 292-293) y probablemente Menghin invitó a Martínez Santa-Olalla a visitar Viena y quizás impartir una conferencia, donde le dedicó una fotografía suya (ASO 20-6-1948). El estallido de la Segunda Guerra Mundial impidió nuevos contactos personales entre ambos como ha mostrado Gracia (2008a, 2008b) en detalle. Cuando Menghin vino a España en 1942 no lo visitó y la comunicación fue epistolar.

Martínez Santa-Olalla (1946: 53) refleja la influencia del trabajo de campo de Menghin en Egipto en su obra principal, en el capítulo del Neolítico Reciente, "Del 3500 al 2000 tenemos el neolítico puro o reciente español (...) Ahora se hace sentir una influencia progresiva del Oriente mediterráneo y de Egipto a través del Norte de África”. Más en concreto, entre el 3000-2000 a.C., aparece una cultura con "indudables paralelos con el neolítico sahariano, consecuencia última del neolítico egipcio, especialmente del grupo badariense y culturas asociables (incluyendo (...) de época plenamente dinástica), y que llamamos cultura iberosahariana", la cual "ofrece como gran novedad (...) el conocimiento del metal y la arquitectura con (...) los sepulcros megalíticos" (Martínez Santa-Olalla 1946: 55-56).

No obstante, para la Edad del Bronce Final, Martínez Santa-Olalla valoraba más la investigación de von Merhart ya que Menghin no trabajaba el período. Almagro Basch inició su formación en Viena por sugerencia de Obermaier. Durante su estancia como becario entre diciembre de 1935 y febrero 1936 (JAE/4-199/7-8; Díaz-Andreu 1996: 208) para trabajar sobre la invasión céltica de la Península Ibérica, Martínez Santa-Olalla le recomendó marcharse cuando pudiera a Marburg por su mejor biblioteca y por contar con la supervisión de von Merhart, especialista en Campos de Urnas (ASO/4-8 28-1-1936). Acabó admitiendo "tenía Vd. mucha razón al aconsejarme que por aquí podía trabajar mejor que en Viena" (ASO/48 4-3-1936; Mederos 2011-12: 342-343).

Menghin fue capturado por los norteamericanos en junio de 1945. Estuvo internado en los campos de prisioneros de Ludwigsburg (BadenWurtemberg) y Darmstadt (Hesse) hasta febrero de 1947, cuando fue liberado, pero al seguir abierto un proceso contra él, decidió emigrar a Argentina. Frente a otros colegas europeos que ignoraron su petición de ayuda, Martínez SantaOlalla le respondió (carta de 15 de junio) prestándole toda la posible, aun sabiendo que Menghin había hecho caso a los comentarios desfavorables sobre él de Almagro Basch (Gracia 2008a: 139142, 2008b: 13-16, 2009: 311-318). Influyeron tres razones. Por una parte, él mismo había sido prisionero en campos de concentración franceses durante la Guerra Civil: entre enero y marzo de 1938 en La Morisca (Port Vendres, Pirineos Orientales) y hasta abril en Chomérac (Ardeche). En segundo lugar, su compromiso ideológico con el Tercer Reich hasta el final de la Segunda Guerra Mundial le obligaba moralmente a ayudar a sus camaradas alemanes y austriacos. En tercer lugar, apreciaba la trayectoria científica de Menghin, cuya influencia se plasma en el origen egipcio de su Neolítico Final Ibero-Sahariano. El aprecio se proyectaba al plano personal, conservó la foto firmada por Menghin en 1938 en la mesa de su despacho del Seminario de Historia Primitiva (ASO 24-7-1948) y valoró siempre sus opiniones. La ayuda se plasmó en cartas al Embajador de España en Argentina, José María de Areilza, que apoyó significativamente a Menghin, y a Claudio Sánchez-Albornoz y Menduiña (ASO 20-6-1948), profesor de Historia en la Universi- 
dad de Buenos Aires, con el que Menghin (1948b) comenzó a colaborar inmediatamente en los $\mathrm{Cua}$ dernos de Historia de España. Le remitió también una carta para Eva Perón, relativa al alojamiento familiar (ASO 28-9-1948), que al final no fue necesaria.

Según la correspondencia Menghin se apoyó en Martínez Santa-Olalla y probablemente también en Almagro Basch. No hay cartas conservadas con este último antes de 1950, pero Almagro tenía buena amistad con su antiguo profesor, Sánchez-Albornoz y con Areilza de la etapa de la Guerra Civil, cuando era alcalde de Bilbao y Almagro Basch dirigía el diario Hierro. Es llamativo que, en la misma fecha, Menghin escribiera simultáneamente a ambos arqueólogos, aprovechando el mismo encabezado (ASO 15-1-1950; MAC 15-1-1950). Por entonces, Martínez SantaOlalla aún trataba de traer a España a dos ayudantes vieneses de Menghin: el SS-Obersturmführer, Teniente Kurt Willvonseder (ASO 2-9-1948; 8-9-1948; 28-9-1948; 21-10-1949) y el croata Conde de Orssich-Slavetich, su ayudante entre 1943-1945 (ASO 9-3-1950; 7-12-1950; 271-1951).

Hacia 1952, Menghin muestra señales de desesperación por la ineficacia de Martínez Santa-Olalla. Le había remitido un artículo para el III Congreso Internacional de Africanistas Occidentales (Nigeria 1949), al que Martínez SantaOlalla no pudo asistir al no autorizársele salir del país (Mederos 2003-04: 38-39). "Ya le pregunté varias veces sobre el destino de mi manuscrito africano, que Ud. pidió (...) con tanta urgencia"; la paralización durante 5 años de la revista "'Actas y Memorias" después de n[úme] ro. XXII" de 1947 (ASO 30-4-1952); el "aplazamiento del [I] Curso de Arqueología de Campo" al que le había invitado, finalmente celebrado el año siguiente en Granada (Alonso del Real 1953-54); la devolución de su manuscrito africano enviado para el congreso en Nigeria "sin una línea de explicación" (ASO 16-8-1952). A ello se añadió el empeño de Martínez SantaOlalla en traducir un libro de Pía Laviosa Zambotti, la cual le había negado su ayuda tras la guerra (ASO 8-9-1948), "Lo encuentro muy mal, lleno de errores materiales e ideas confusas" (MAC 14-12-1951).

En contraposición, Almagro Basch fue ganando enteros con la publicación regular de Ampurias, la mejor revista española de entonces: "Ten- go en mi posesión 'Ampurias' I-IV y IX-XI. Sería posible completar la serie?" (MAC 8-71950), agradeciéndole "una gestión en mi favor incluso para quedarme en España" pero "Hasta la fecha no tengo pasaporte, 8 años después de la guerra" (MAC 9-1-1954; Gracia 2012: 255). A la vez, Almagro Basch siempre le advertía sobre su colega madrileño, "En fin (...) todo lo que venga de Santaolalla tu lo tomes un poco en cuarentena" pues "fue apartado del C[onferencia]. I[nternacional]. $\mathrm{A}$ [fricanistas]. $\mathrm{O}$ [ccidentales]. por su intemperancia y jaleos que allí armó" (MAC 9-61950; Gracia 2012: 254).

La consolidación de Menghin en Argentina no fue fácil. Aunque contaba con el apoyo de Imbe1loni, director del Museo Etnográfico de la Universidad de Buenos Aires desde 1947, fue contratado desde el 1 de septiembre y no inmediatamente como se había sugerido. Tampoco pudo impartir docencia hasta 1953, y solo entonces ad honorem en la Facultad y Museo Etnográfico, ya con 65 años. Amplió sus ingresos como investigador al añadir un pequeño contrato en la Facultad y $\mathrm{Mu}-$ seo de la Plata desde 1949 para financiar sus investigaciones de campo junto a Rex González. Por la documentación austriaca, no parece que hubiera especial interés en extraditarlo. La Fiscalía de Viena esperaba detenerlo cuando visitase Austria de nuevo. En todo caso, Menghin fue muy cauto. Desde su llegada en 1948 no viajó fuera de Argentina hasta noviembre de 1956, cuando realizó su primera y única salida, invitado por el Centro de Estudios Antropológicos de la Universidad de Santiago de Chile. La explicación que dio a Martínez Santa-Olalla, que lo había invitado al III Congreso Internacional de Africanistas del Oeste, fue: "no deseo cooperar en instituciones internacionales antes de haber recibido plena reparación por todo lo que tuve que sufrir de los Americanos y los Austriacos. Estoy preparado de trabajar con cualquiera persona particular honrada, pero lo debo a mi honor de rehusar la colaboración con instituciones oficiales e internacionales" (ASO 23-9-1949).

La ocupación aliada de Austria finalizó en 1955. Menghin en enero de 1956 solicitó el sobreseimiento del proceso penal abierto contra él desde el 25 de junio de 1945. El Canciller austriaco lo concedió en diciembre de 1956 (Urban 1996: 12-13, doc. 5-6). Es llamativo que solo al año siguiente, con 69 años, Menghin fuera nombrado Profesor Interino de Prehistoria de la Fa- 
cultad de Ciencias Naturales y Museo de la Universidad Nacional de La Plata. Un año después, con motivo de la creación de una nueva Licenciatura de Ciencias Antropológicas de la Facultad de Filosofía y Letras de la Universidad de Buenos Aires, se encargó en 1958 de la Cátedra de Prehistoria General y del Viejo Mundo, donde obtuvo dedicación exclusiva en 1960. Se jubiló en esa institución en 1968, al cumplir los 80 años.

La ideología nacional-socialista de Menghin favoreció sus primeros contactos con Martínez Santa-Olalla desde 1938, al exiliarse Obermaier y sustituirle de forma interina en su cátedra de Madrid en 1939. En cambio con el declive militar alemán desde 1943 se convirtió en un lastre en la trayectoria académica de Martínez SantaOlalla que no fue autorizado a viajar a Alemania desde 1942 (Gracia 2009: 319-321) y después de la guerra tampoco a congresos en el extranjero (Mederos 2003-04: 36-38). A la vez Menghin se vio obligado a exiliarse en Argentina desde 1948, desapareciendo del panorama académico europeo.

En el plano personal, pero también científico, Menghin confió más en su antiguo discípulo en Viena, Almagro Basch, que en Martínez SantaOlalla, cuya obra científica, desde 1941 fue muy pobre (Mederos 2012a: 71). Ello acabó perjudicándole en su intento de convertirse en el referente en España de los trabajos arqueológicos de las SS-Ahnenerbe (Gracia 2008a, 2008b), no dudando Menghin en hablar en su contra en 1942.

Desde un punto de vista científico, Menghin y Martínez Santa-Olalla confluyeron en su interés por las líneas de trabajo que ya les interesaban antes de la guerra: la influencia egipcia en el Neolítico Final ibero-sahariano y el papel clave de la Península Ibérica en la difusión de la metalurgia del cobre y el megalitismo hacia Europa desde Egipto. Las discrepancias científicas también permanecieron como se aprecia en la recensión de Menghin (1948a) al libro de Martínez Santa-Olalla (1946).

Finalmente, la relación entre Menghin, catedrático desde 1922, y Martínez Santa-Olalla, catedrático desde 1936, 15 años después, fue siempre jerárquica y desigual. La evidente generosidad del segundo que ayudó a Menghin a instalarse en Argentina tuvo como única correspondencia el envío de dos artículos para su publicación, uno en 1939 (Menghin 1941) y otro que quedó inédito en 1949.

\section{AGRADECIMIENTOS}

A Salvador Quero por su permanente amabilidad en la consulta de la documentación del Archivo Julio Martínez Santa-Olalla (ASO) y a Alberto González por el acceso al Fondo Documental Pérez de Barradas (FD2005), ambos en el Museo de San Isidro de Madrid. Francisco Gracia comentó el texto y nos cedió generosamente las cartas entre Menghin y Almagro Basch entre 1950-1956, depositadas en el archivo del Museo Arqueológico de Cataluña (MAC). Agradecemos las sugerencias de los dos evaluadores y del equipo de dirección de la revista. Este trabajo se adscribe al Grupo de Investigación Hum F-003 de la Universidad Autónoma de Madrid, sobre estudios historiográficos, dirigido por Juan Blánquez.

\section{BIBLIOGRAFÍA}

Almagro Basch, M. 1940: "El Hallazgo de la Ría de Huelva y el Final de la Edad del Bronce en el Occidente de Europa". Ampurias 2: 85-143.

Almagro Basch, M. 1941: "Menghin, O.: Weltgeschichte der Steinzeit. Segunda edición. Viena, 1940". Ampurias 11: 158.

Alonso del Real y Ramos, C. 1953-54: "España. Curso Internacional de Arqueología de Campo". Runa, 6 (1-2): 295-296.

Alonso del Real y Ramos, C. 1991: La Prehistoria. Ciclo de conferencias para doctorado (Madrid, 1986-87). Diputación Provincial de Pontevedra. Pontevedra.

Anón. 1942: El arqueólogo alemán, profesor Menghin, en la Universidad. La Vanguardia. Barcelona, 18 de junio: 6 .

Anón. 1944: Conferencia del profesor Martínez SantaOlalla sobre arqueología aérea. ABC. Madrid, 30 de marzo: 14.

Blaschitz, E. 2002: "Austrian National Socialist in Argentina after 1945”. En O. Rathkolb (ed.): Revisiting the National Socialist Legacy. Coming to Temps with Forced Labor, Expropiation, Compensation and Restitution. Studienverlag. Innsbruck: 226-240.

Demoule, J. P. 2002: “Comments. Religion, Politics, and Prehistory. Reassessing the Lingering Legacy of Oswald Menghin”. Current Anthropology 43 (4): 576-577.

Díaz-Andreu García, M. 1996: “Arqueólogos españoles en Alemania en el primer tercio del siglo XX. Los becarios de la Junta de Ampliación de Estudios 
e Investigaciones Científicas". Madrider Mitteilungen 37: 205-224.

Díaz-Andreu, M. y Ramírez, M. E. 2001: “La Comisaría General de Excavaciones Arqueológicas (1939-1955). La administración del patrimonio arqueológico en España durante la primera etapa de la dictadura franquista". Complutum 12: 325-343.

Fontán, M. 2005: Oswald Menghin: ciencia y nazismo. El antisemitismo como imperativo moral. Biblioteca Nuestra Memoria, Fundación Memoria del Holocausto. Buenos Aires.

Geehr, R. S. 1986: "Oswald Menghin. Ein Vertretel der katholischen Nationalen". Geistiges Leben in Österreich der Ersten Republik (Wien, 1980 y 1982): 9-24. Wien-Munchen.

Geehr, R. S. 2003: The Aesthetics of Horror: the Life and Thought of Richard von Kralik. Brill Academic. Leiden.

González, A. R. 2008: “Ongamira, Intihuasi y otros recuerdos". Revista del Museo de Antropología 1 (1): 25-28. http://publicaciones.ffyh.unc.edu.ar/index.php/ antropologia/article/view/3/12 (consulta 13-VI-2014).

Gracia Alonso, F. 2008a: "Las relaciones entre los arqueólogos españoles y la Alemania nazi (19391945): la influencia de Das Ahnenerbe en España. Un estudio preliminar”. En G. Mora, C. Papí y M. Ayarzagüena (eds.): Documentos inéditos para la historia de la arqueología (Madrid 2007): 129-154. Memorias de la Sociedad Española de Historia de la Arqueología 1. Madrid-Toledo.

Gracia Alonso, F. 2008b: "Relations between Spanish Archaeologist and Nazi Germany (1939-1945). A preliminary examination of the influence of Das Ahnenerbe in Spain". Bulletin of the History of Archaeology 18 (1): 4-24.

Gracia Alonso, F. 2009: La arqueología durante el primer franquismo (1939-1956). Bellaterra Arqueología. Barcelona.

Gracia Alonso, F. 2012: Arqueologia i política. La gestió de Martín Almagro Basch al capdavant del Museu Arqueolòic provincial de Barcelona (1939-1962). Universitat de Barcelona-Museu d'Arqueologia de Catalunya. Barcelona.

Grüttner, M. 1995: Studenten im Dritten Reich. Schoeningh. Paderborn.

Guber, R. y Visacovsky, S. 2006: "The Birth of Ciencias Antropológicas at the University of Buenos Aires, 1955-1965". Histories of Anthropology Annual 2: $1-32$.

Heiber, H. 1991: Universität unterm Hakenkreuz. Part 1. Der Professor im Dritten Reich. Saur. München.

Junker, H. 1932: "Vorbericht über die von der Akademie der Wissenschaften in Wien in Verbindung mit dem Egyptiska Museet in Stockholm unternommenen Grabungen auf der neolitischen Siedlung von Merimde-Benisalâlme vom 6. November 1931 bis 20. Jänner 1932". Anzeiger der Akademie der Wissenschaften in Wien, philosophisch-historische Klasse 69: 36-82 y 99-100.

Junker, H. 1933: "Vorläufiger Berich über die von der Akademie in Verbindung mit dem Egyptiska Museet in Stockholm unternommenen Grabungen auf der neolitischen Siedlung von Merimde-Benisalâlme vom 2. Jänner 1931 bis 20. Februar 1933". Anzeiger der Akademie der Wissenschaften in Wien, philosophisch-historische Klasse 70: 54-97.

Junker, H. 1934: "Vorbericht über die fünfte von der Akademie der Wissenschaften in Wien und dem Egyptiska Museet in Stockholm unternommenene Grabung auf der neolitischen Siedlung MerimdeBenisalâlme vom 13. Februar bis 26. März 1934". Anzeiger der Akademie der Wissenschaften in Wien, philosophisch-historische Klasse 71: 118-132.

Junker, H. 1940: "Vorbericht über die siebente Grabung der Akademie der Wissenschaften in Wien auf der vorgeschichtlichen Siedlung MerimdeBenisalâlme vom 25. Januar bis 4. April 1939". Anzeiger der Akademie der Wissenschaften in Wien, philosophisch-historische Klasse 77: 3-17.

Junker, K. 2002: "Comments. Religion, Politics, and Prehistory. Reassessing the Lingering Legacy of Oswald Menghin". Current Anthropology 43 (4): 578.

Kohl, Ph. L. y Pérez Gollán, J. A. 2002: "Religion, Politics, and Prehistory. Reassessing the Lingering Legacy of Oswald Menghin". Current Anthropology 43 (4): 561-586.

Lafón, C. R. 1967: “Recordación del Doctor Fernando Márquez Miranda”. Runa 10 (1-2): 7-61.

Luca de Tena, T.; Calvo, L. y Peicovich, E. 1976: Yo, Juan Domingo Perón. Planeta-Sudamericana. Barcelona-Buenos Aires.

Martínez, T. E. 1996: Las memorias del general. Una crónica sobre los años 70 en Argentina. Planeta. Barcelona-Buenos Aires.

Martínez Santa-Olalla, J. 1941: “Esquema paletnológico de la Península hispánica”. En J. Martínez Santa- Olalla (ed.): Corona de Estudios que la Sociedad Española de Antropología, Etnología y Prehistoria dedica a sus mártires I. Consejo Superior de Investigaciones Científicas. Madrid: 141-166.

Martínez Santa-Olalla, J. 1945: "Presencia de la Comisaría General de Excavaciones Arqueológicas". Actas y Memorias de la Sociedad Española de Antropología, Etnografía y Prehistoria 20 (1-4): 109-118.

Martínez Santa-Olalla, J. 1946: Esquema paletnológico de la Península Hispánica. Seminario de Historia Primitiva. Madrid.

Mederos Martín, A. 2003-04: "Julio Martínez SantaOlalla y la interpretación aria de la Prehistoria de España (1939-1949)". Boletín del Seminario de Estudios de Arte y Arqueología 69-70: 13-55. 
Mederos Martín, A. 2010-11: "Hugo Obermaier, el duro camino hacia la cátedra de Historia Primitiva del Hombre (1877-1922)". Homenaje a D. Manuel Santonja Alonso. Boletín de la Asociación Española de Amigos de la Arqueología 46: 237-261.

Mederos Martín, A. 2011-12: "Martín Almagro Basch, formación y consolidación como catedrático de Prehistoria (1911-1943)". Boletín del Seminario de Estudios de Arqueología, 77-78: 335-416.

Mederos Martín, A. 2012a: “El periplo académico de Julio Martínez Santa-Olalla en la década de los cincuenta”. En L. Roldán y J. Blánquez (eds.): Julio Martínez Santa-Olalla y el descubrimiento arqueológico de Carteia (1953-1961) (Cádiz 2012): 68-81. Madrid.

Mederos Martín, A. 2012b: "El proyecto de Antonio Tovar de una exposición de Canarias en 1941 y la consolidación de las Comisarías Insulares de Excavaciones como respuesta al intento de Hitler de anexionarse una isla canaria". Lucentum 31: 207-226.

Mederos, A. y Escribano, G. 2011: Julio Martínez Santa-Olalla, Luis Diego Cuscoy y la Comisaría Provincial de Excavaciones Arqueológicas de las Canarias Occidentales (1939-1955). Canarias Arqueológica Monografías 5, Museo Arqueológico de Tenerife. Sevilla-Tenerife.

Menghin, O. F. A. 1925: "Die Tumbakultur am unteren Kongo und der westafrikanische Kulturkreis". Anthropos 20: 516-557.

Menghin, O. F. A. 1931: Weltgeschichte der Steinzeit. Anton Schroll. Wien.

Menghin, O. F. A. 1934a: Geist und Blut. Grundstätzliches um Rasse, Sprache, Kultur und Volkstum. Anton Schroll. Wien.

Menghin, O. F. A. 1934b: "Die neolithische Ansiedlung von Merimde-Benisalame und ihre Bedeutung für die Entwicklung des Neolithikums in Westeuropa". Proceedings of the First International Congress of Prehistoric and Protohistoric Sciences (London 1932): 177-180. Oxford.

Menghin, O. F. A. 1938: "Geist und Boden". Die Warte 3 (2): 1-3.

Menghin, O. F. A. 1939: "Urgeschichtliche Feldforschungen in Nordtirol 1937 und 1938". Wiener Prähistorische Zeitschrift 26: 22-51.

Menghin, O. F. A. 1941: "Egipto y la Península Hispánica”. En J. Martínez Santa-Olalla (ed.): Corona de Estudios que la Sociedad Española de Antropología, Etnología y Prehistoria dedica a sus mártires I. Consejo Superior de Investigaciones Científicas. Madrid: 167-184.

Menghin, O. F. A. 1942a: "El origen del pueblo del antiguo Egipto". Ampurias 4: 25-41.

Menghin, O. F. A. 1942b: "Urgeschichtliche Feldforschungen in Nordtirol 1939-1941". Wiener Prähistorische Zeitschrift, 29: 156-194.
Menghin, O. F. A. 1948a: "Martínez Santa-Olalla, Julio. Esquema paletnológico de la Península Hispánica. 2. "ed., Madrid, 1946". Runa 1 (1-2): 298-300.

Menghin, O. F. A. 1948b: "Historia de España dirigida por R. Menéndez Pidal. Tomo I, España Prehistórica. Volumen I, por E. Hernández-Pacheco, F. Hernández-Pacheco, L. de Hoyos Sáinz, Martín Almagro, A. del Castillo, Juan Maluquer de Motes y Juan de Mata Carriazo; Espasa-Calpe, S.A.; Madrid, 1947'. Cuadernos de Historia de España 9: 200-210.

Menghin, O. F. A. 1949a: "El Tumbiense africano y sus correlaciones mundiales". Runa 2 (1-2): 89125.

Menghin, O. F. A. 1949b: "Archäologische Feldforschungen in Ost-tirol 1943 und 1944”. Der Schlern 23: 232-242 y 287-298.

Menghin, O. F. A. 1956: "Alois Menghin”. Der Schlern 30: 98-99.

Menghin, O. F. A. y Amer, M. 1932: The Excavations of the Egyptian University in the Neolithic Site at Maadi. First Preliminary Report (Season 1930-31). Egyptian University, Faculty of Art. Misr-Sokkar Press. Cairo.

Menghin, O. F. A. y Amer, M. 1936: The Excavations of the Egyptian University in the Neolithic Site at Maadi. Second Preliminary Report (Season 1932). Egyptian University, Faculty of Art. Misr-Sokkar Press. Cairo.

Narr, K. J. 1974: “Oswald Menghin”. Prähistorische Zeitschrift 49: 1-5.

Obermaier Grad, H. 1912: Der Mensch der Vorzeit. Berlin-München-Wien.

Ortega, A. I. y Quero, S. 2002: “Julio Martínez SantaOlalla. 1905, Burgos-12 Febrero de 1972, Madrid”. Bifaces y elefantes. La investigación del Paleolítico Inferior en Madrid. Zona Arqueológica 1: 194-213.

Pauley, B. F. 1992: From Prejudice to Persecution. A History of Austrian Anti-Semitism. University of North Carolina Press. Chapel Hill.

Perón Sosa, J. D. 1950: Toponimia patagónica de etimología araucana. Biblioteca Nacional. Buenos Aires.

Pittioni, R. 1974: “Oswald Menghin 1888-1973”. Archaeologia Austriaca 55: 1-6.

Politis, G. G. 2002: "Comments. Religion, Politics, and Prehistory. Reassessing the Lingering Legacy of Oswald Menghin". Current Anthropology 43 (4): 580-581.

Rosar, W. 1971: Deutsche Gemeinschaft, Seyss-Inquart und der Anschluss. Europa-Verlag. WienFrankfurt-Zurich.

Schenk, D. 2001: Auf dem rechten Auge blind. Die braunen Wurzeln des BKA. Kiepenheuer und Witsch Verlag. Köln.

Schobinger, J. 1958-59: "Significación del Profesor Dr. Osvaldo F. A. Menghin para el conocimiento de 
la prehistoria sudamericana. Dedicado al Profesor Dr. Osvaldo F. A. Menghin en su $700^{\circ}$ aniversario y en el décimo de su llegada a la Argentina". Anales de Arqueología y Etnología de la Universidad Nacional de Cuyo 14-15: 11-18.

Schobinger, J. 1974-75: "Prof. Don Osvaldo F. A. Menghin (1888-1973)". Ampurias 36-37: 321-326.

Schobinger, J. 2008: "Entrevista al Dr. Juan S. Schobinger (Mendoza, 10 de julio de 2008)". En R. Barberena: Vida de un arqueólogo, petroglifos y santuarios de alta montaña: entrevista con el Dr. Juan S. Schobinger. Relaciones de la Sociedad Argentina de Antropología 33: 3-15.

Soprano, G. 2009: "La Antropología Física entre la universidad y el Estado. Análisis de un grupo académico universitario y sus relaciones con las políticas públicas del Instituto Étnico Nacional (19461955)". Estudios Sociales 37: 63-95.

Taschka, S. 2006: Diplomat ohne Eigenschaften? Die Karriere des Hans Heinrich Dieckhoff (18841952). Steiner Verlag. Stuttgart.
Trebsche, P. 2005: "Zu den internationalen Beziehungen der Urgeschitsforschung in Oberösterreich während der Zwischenkriegs- und Nazizeit". En M. Chytráček, H. Gruber, J. Michálek, M. M. Rind y K. Schmotz (eds.): Archäologische Arbeitsgemeinschaft Ostbayern/West- und Südbohem 14, Verlag Marie Leidorf. Rahden/Westfalia: 178-188.

Urban, O. H. 1996: "Er war der Mann zwischen den Fronten. Oswald Menghin und das Urgeschichtliche Institut der Universität Wien während der Nazizeit". Archaeologia Austriaca 80: 1-24.

Werner, J. 1946: "Las excavaciones del Seminario de Historia Primitiva del Hombre, en 1941, en el cementerio visigodo de Castiltierra (Segovia)". Cuadernos de Historia Primitiva 1 (1): 46-50.

Whiteside, A. 1965: "Austria”. En H. Rogger y E. Weber (eds.): The European Right. A Historical Profile. University of California Press. Berkeley-Los Ángeles-Cambridge University Press. Cambridge: 308-363. 